Florida International University FIU Digital Commons

FIU Electronic Theses and Dissertations

University Graduate School

7-1-2016

\title{
Regulation of Particle Uptake by PP2A/B56 and LKB1 in Dictyostelium Discoideum
}

Mujataba Rahiman Sharief

Florida International University, mshar026@fiu.edu

DOI: $10.25148 /$ etd.FIDC000781

Follow this and additional works at: https://digitalcommons.fiu.edu/etd

Part of the Biochemistry Commons, Cell Biology Commons, and the Molecular Biology Commons

\section{Recommended Citation}

Sharief, Mujataba Rahiman, "Regulation of Particle Uptake by PP2A/B56 and LKB1 in Dictyostelium Discoideum" (2016). FIU Electronic Theses and Dissertations. 2539.

https://digitalcommons.fiu.edu/etd/2539

This work is brought to you for free and open access by the University Graduate School at FIU Digital Commons. It has been accepted for inclusion in FIU Electronic Theses and Dissertations by an authorized administrator of FIU Digital Commons. For more information, please contact dcc@fiu.edu. 


\section{FLORIDA INTERNATIONAL UNIVERSITY}

Miami, Florida

\section{REGULATION OF PARTICLE UPTAKE BY PP2A/B56 AND LKB1 DICTYOSTELIUM DISCOIDEUM}

A dissertation submitted in partial fulfillment of the requirements for the degree of DOCTOR OF PHILOSOPHY in BIOCHEMISTRY

by

Mujataba Rahiman Sharief 
To: Dean Michael R. Heithaus

College of Arts, Sciences and Education

This dissertation, written by Mujataba Rahiman Sharief, and entitled Regulation of Particle Uptake by PP2A/B56 and LKB1 in Dictyostelium discoideum, having been approved in respect to style and intellectual content, is referred to you for judgment.

We have read this dissertation and recommend that it be approved.

Xiaotang Wang

Yukching Tse-Dinh

Lidia Kos

Mauricio Rodriguez-Lanetty

Lou W. Kim, Major Professor

Date of Defense: July 1, 2016

The dissertation of Mujataba Rahiman Sharief is approved.

Dean Michael R. Heithaus
College of Arts, Sciences and Education

College of Arts, Sciences and Education

Andrés G. Gil

Vice President for Research and Economic Development And Dean of University Graduate School

Florida International University, 2016 


\section{DEDICATION}

I dedicate this dissertation to my parents, Atha Ulla Sheriff and Anees Fathima for their Immense support and confidence in me. I also dedicate this dissertation to my grandfather Late Abdul Wajid for his unconditionally love towards me. 


\section{ACKNOWLEDGMENTS}

I would like to thank my mentor, Dr. Lou W. Kim, for his immense support and mentoring during these years. My committee members, Dr. Lidia Kos, Dr. Xiaotang Wang, Dr. Yukching Tse-Dinh and Dr Mauricio Rodriguez-Lannety have also been a great help with their questions and feedback. I would like to express my gratitude to my lab members, Dr. Marbelys Rodriguez, Ms. Maria Pulido, Cong Gu, Dr. Seon-Hee Hwang, Dr. Tong Sun, Adwait Kabra, Dr. Boris Castillo and Mrs. Bohye Kim for their valuable suggestions, discussions and willingness to help. I would like to thank the Department of Chemistry and Biochemistry for providing me a teaching assistantship throughout my graduates studies. Lastly, I would like to thank my parents and friends for providing me with the moral support and having confidence in me. 


\author{
ABSTRACT OF DISSERTATION \\ DICTYOSTELIUM DISCOIDEUM \\ by \\ Mujataba Rahiman Sharief \\ Florida International University, 2016 \\ Miami, Florida \\ Professor Lou W. Kim, Major Professor
}

REGULATION OF PARTICLE UPTAKE BY PP2A/B56 AND LKB1 in

Dictyostelium discoideum, a soil dwelling amoeba which has been widely used as a model organism to study cellular processes such as signal transduction, chemotaxis, endocytosis and exocytosis. The process of phagocytosis in Dicytostelium is largely comparable to that of neutrophils and macrophages in the mammalian system. Neutrophils and macrophages are cells of the innate immune system and they engulf infectious bacteria through phagocytosis. Dictyostelium cells uptake yeast and bacteria for their nutrition through phagocytosis, which is an actin dependent mechanism and is a target of multiple signaling inputs. Recent studies have uncovered different proteins involved in the signaling of particle intake and further studies are required to decipher the intricate mechanism leading to the F-actin rearrangement. Two of the proteins have previously known to be involved in the pathways regulating the F- actin rearrangement name PP2A phosphatase and LKB1 kinase 
The main objective of this project was to determine how these proteins are affecting the two actin driven particle uptake processes, Phagocytosis and Fluid uptake. We showed that ablation of the PsrA gene coding the regulatory subunit of PP2A resulted in a defective phagocytosis, whereas the fluid uptake was normal. We also showed for the first time that there was an increase in the phosphorylation's of some of the PKB substrate proteins in wild type cell. Cells lacking PsrA gene displayed an aberrant phosphorylation of PKB substrate protein when compared to the wild type cells further confirming the involvement of PKB substrate in Phagocytosis.

Further, we looked at the effects of LKB1 kinase on phagocytosis by using a LKB1 knockdown construct introduced into wild type cells. The knock down of LKB1 resulted in a higher rate of phagocytosis while introduction of a LKB1 over expressing construct severely decreased the rate of phagocytosis indicating an inhibitory effect of LKB1. Further more there was an increase in the PKB substrate protein but a different pattern compared to the $p s r A^{-}$cells. We also carried out adhesion assays on LKB1 knockdown cells and the results showed a higher substrate adhesion as compared to the wild type cells, while $p_{s r A}{ }^{-}$cells. 


\section{TABLE OF CONTENTS}

CHAPTER

PAGE

CHAPTER 1 INTRODUCTION ..............................................................................................1

1.1 Dictyostelium as a model organism to study particle uptake................................... 2

1.2 Overall processes of Phagocytosis................................................................. 5

1.3 Phagocytosis requires specific cortical F-Actin remodeling activity ....................... 7

1.4 Regulatory circuits that fine-tune the process of particle uptake.............................. 9

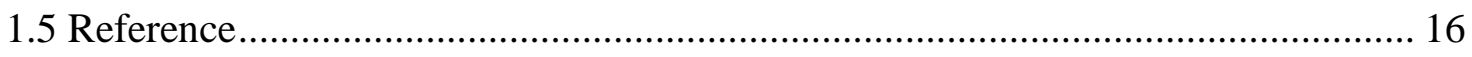

CHAPTER 2. THE ROLE OF PKB SUBSTRATE PHOSPHORYLATION IN PHAGOCYTOSIS AND REGULATION OF THE PARTICLE UPTAKE BY PP2A/B56

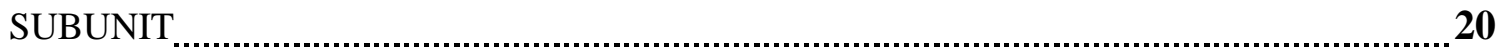

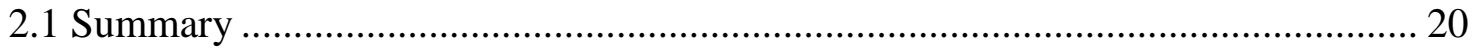

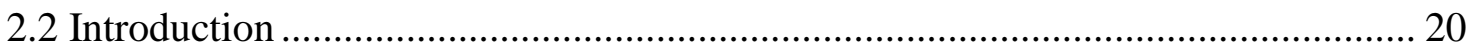

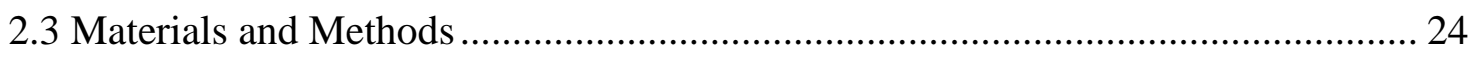

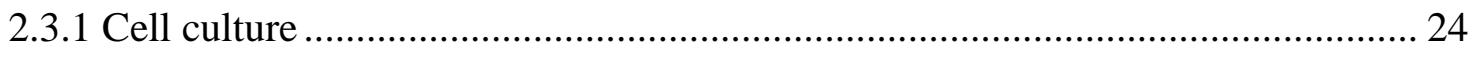

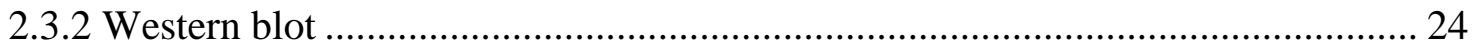

2.3.3 Analysis of Phagocytosis using TRITC labelled yeast ........................................ 25

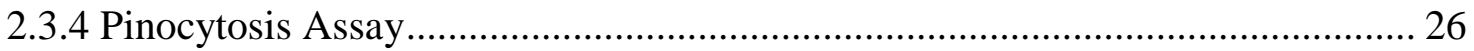

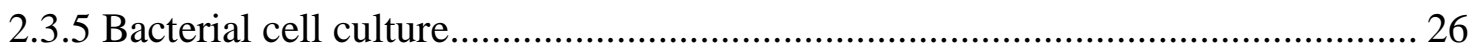

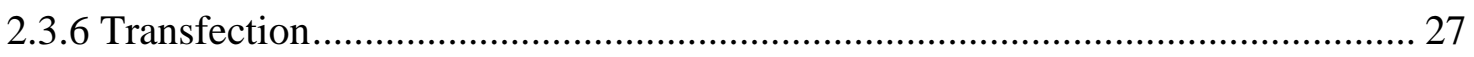

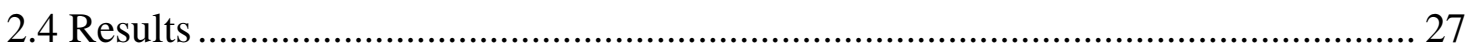

2.4.1 Ras and PI3 kinase is involved in phagocytosis................................................ 27

2.4.2 PKB substrate phosphorylation levels increased during phagocytosis in

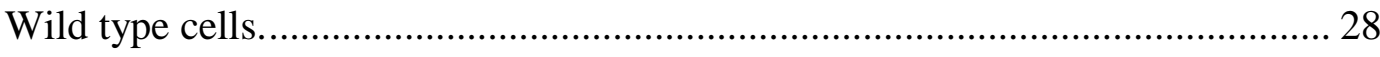


2.4.3 $\mathrm{ras}^{-}$cells have lower levels of phagocytosis and fluid uptake. 30

2.4.4 $\mathrm{psr}^{-}$cells display severely compromised phagocytosis while Fluid uptake was unaffected.

2.4.5 Treatment of psrA- cells with PI3 kinase inhibitor LY 249002 restored the phagocytosis. 32

2.4.6. PKB substrate phosphorylation pattern in $p s r A^{-}$cells were rectified similarly to those of the wild type upon treatment with LY294002 treatment. 33

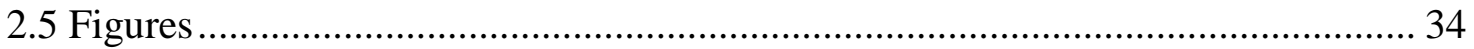

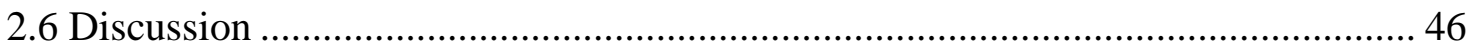

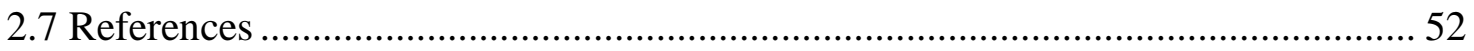

CHAPTER 3: LKB1 INHIBITS PHAGOCYTOSIS AND CELL ADHESION .............................55

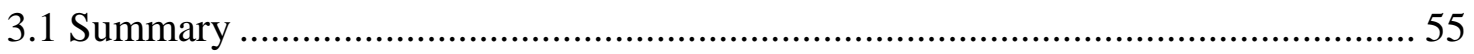

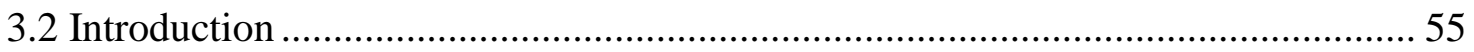

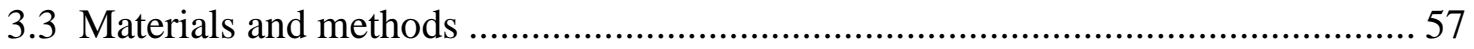

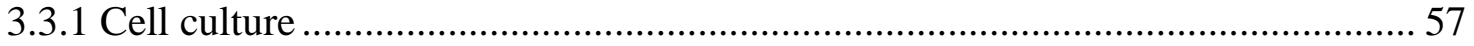

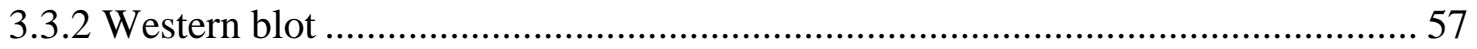

3.3.3 Analysis of Phagocytosis using TRITC labelled yeast ................................... 58

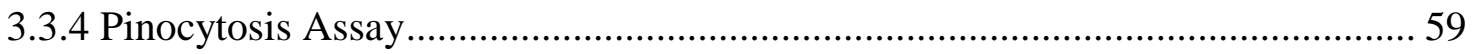

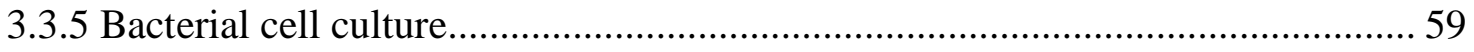

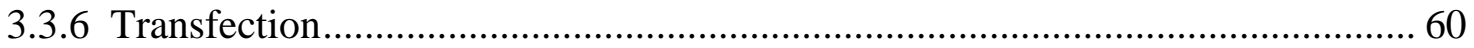

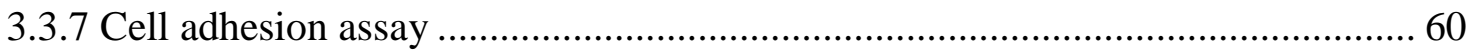

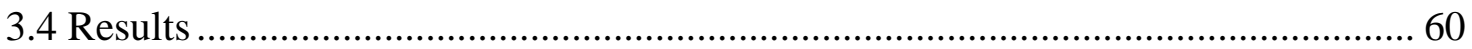

3.4.1 LKB1 inhibits phagocytosis but no effect on fluid uptake.............................. 60

3.4.2 PKB substrate phosphorylation is high in LKB1-RNAi cells and no restoration

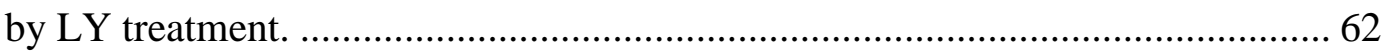

3.4.3 Cell-to-matrix adhesion fluid uptake activity of $L K B 1-R N A i$ and $p s r A^{-}$cells. .... 63

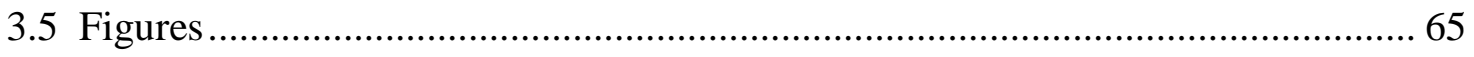

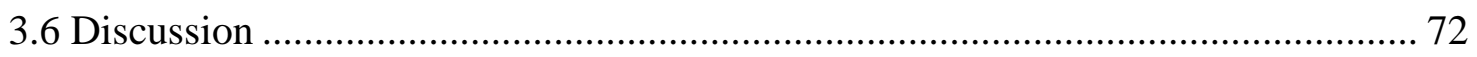

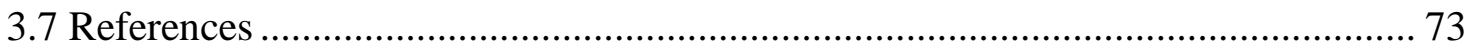


CHAPTER 4 CONCLUSION AND FUTURE DIRECTION ..........................................................75

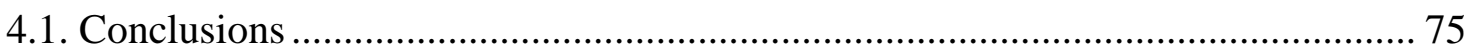

4.2 Dictyostelium as a model for Host- pathogen interaction studies ......................... 79

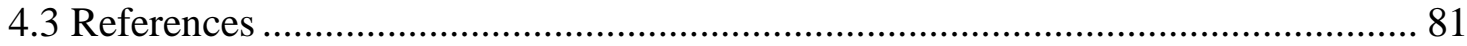

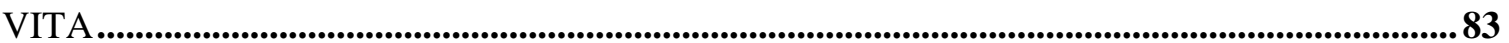




\section{LIST OF FIGURES}

FIGURES

PAGE

FIGURE 1 REGULATION OF ACTIN BY PIP2 2....................................................... 4

FIGURE 2 ROLE OF RAS GTPASES IN PARTICLE UPTAKE ……………………..... 36

FIGURE 3 PIP3 IS INVOLVED IN PHAGOCYTOSIS AND PKB SUBSTRATES

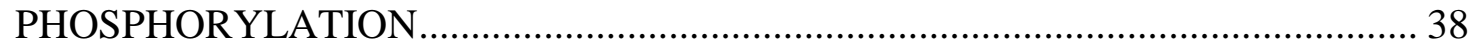

FIGURE 4 PSRA-CELLS DISPLAY A DEFECT IN PHAGOCYTOSIS, BUT MACROPINOCYTOSIS IS NORMAL

FIGURE 5 PSRA- CELLS DISPLAY RESTORATION IN PHAGOCYTOSIS TO WILD TYPE LEVELS AFTER TREATMENT WITH $50 \mu \mathrm{M}$ LY 294002 ...

FIGURE 6 PSRA- CELLS SHOW ABERRANT PKB SUBSTRATE PHOSPHORYLATION. 45

FIGURE 7 PHAGOCYTOSIS OF TRITC YEAST BY LKB1 KNOCKDOWN CELLS AND CELLS OVER EXPRESSING LKB1. 66

FIGURE 8 LKB1 KNOCKDOWN CELLS SHOW ELEVATED LEVELS OF PHAGOCYTOSIS OF TRITC YEAST. 69

FIGURE 9 ADHESION AND FLUID UPTAKE …………………………………... 71

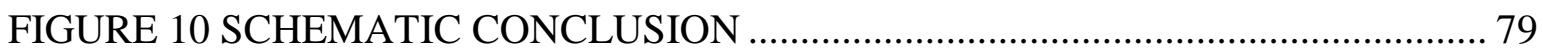


ABS

Absorbance

BSA Bovine serum albumin cAMP 3'-5' -cyclic adenosine monophosphate

DB. Developmental buffer

DNA Deoxyribose nucleic acid

FITC Fluoroscene Isothiocyanate

GAP GTPase-activating protein

GEF Guanine nucleotide exchange factor

GFP Green fluorescent protein

GSK3 Glycogen Synthase Kinase 3

GST Glutathion S-tansferase

GTPase Enzyme that hydrolyzes guanosine triphosphate

$\mathrm{Hr}$ Hour

$\mathrm{IP}_{3}$ Inositol-1,4,5-Triphosphate JH10 Dictyostelium auxotrophic wild type strain

$\mathrm{kD}$ Kilo Dalton 
$\mathrm{L}$

Liter

LB

Luria broth

LY294002

Inhibitor of phosphoinositide 3-kinases

$\mathrm{mg}$

Milligram

$\min$

Minute

$\mathrm{ml}$ Milliliter

$\mathrm{mm}$ Millimeter

$\mathrm{mM}$ Millimolar

PAKa p21 Activated Protein A

PCR Polymerase chain reaction

PDGF Platelet-derived growth factor

PI3K Phosphatidylinositol-3-kinase

PIP3 Phosphatidylinositol 3,4,5-triphosphate

PKA Protein Kinase A

PKBA Protein Kinase BA

PKBR1 Protein Kinase B-related 1 PP2A Protein Phosphatase 2A Ras Rat sarcoma 
SD Standard deviation

$\mathrm{s} / \mathrm{sec}$ Second

TorC2 Target of Rapamicin Complex 2 TRITC Tetramethylrhodamine $\mu \mathrm{g}$ Microgram $\mu l$ Microliter $\mu \mathrm{m}$ Micrometer $\mu \mathrm{M}$ Micromolar $\mu$ Micro$\mathrm{Wt}$ Wild type 


\section{CHAPTER 1 INTRODUCTION}

Eukaryotic cells can engulf fluid and particles from the extracellular environment and move them to the inside of the cell by different processes collectively termed as endocytosis. Endocytosis is classified as Clathrin dependent and Clathrin independent events. Two of the endocytotic processes that are the foci of this dissertation are phagocytosis and macropinocytosis, which are actin dependent and clathrin independent pathways. Phagocytosis is a function of professional phagocytes like macrophages, neutrophils, and Dictyostelium a cellualr (Haas 2007; Stuart \& Ezekowitz 2005). Phagocytosis involves particle adhesion on a specific membrane receptor of the host. Macropinocytosis, in contrast, is generally a receptor independent constitutive process operating in cells like dendritic cells and single celled amoeba like Dictyostelium. Both macropinocytosis and phagocytosis initially form F-Actin supported membrane structures of appropriate size and shape that can facilitate further extension of the host membrane and complete internalization by the cup sealing. Right after internalization, F-Actin structures on the vesicle rapidly dissemble and start to go through vesicle trafficking by fusion with small vesicles loaded with specific proteins guiding to their destinations and endowing new function progressively. These events of macropinosomes and phagosomes

are closely interlinked with specific phosphoinositides, especially $\mathrm{PI}(3) \mathrm{P}, \mathrm{PI}(4,5) \mathrm{P} 2$ and $\mathrm{PI}(3,4,5) \mathrm{P} 3$, and F-Actin remodeling. Consequently, signaling networks that spatially and temporally modulate phosphoinositides and F-Actin remodeling activity will significantly affect the speed and/or efficiency of uptake and intracellular trafficking afterwards. 
Most of these events are well conserved between mammalian phagocytes and Dictyostelium, and thus the use of Dictyostelium discoideum as a model system has been fruitful. Recent insight on the stochastic F-Actin remodeling gained from Dictyostelium uncovered that the self-organizing F-Actin waves simulate phagocytic cup structure (Ishikawa-Ankerhold et al. 2010). The self-organizing F-Actin wave is one of several types of stochastic F-Actin remodeling activity, which is independent from heterotrimeric G proteins and Arp2/3 organiser Scar (Gerisch et al. 2009). Further mechanistic insights on the regulatory signaling networks that affect stochastic F-Actin remodeling will significantly improve the current knowledge of phagocytosis and macropinocytosis, considering that several mammalian cells also display stochastic F-Actin remodeling

\subsection{Dictyostelium as a model organism to study particle uptake.}

Dictyostelium discoideum, a soil dwelling amoeba has gained popularity in recent years as a model organism to study different cellular processes. Dictyostelium has multiple signaling pathways, which show significant level of conservation with the mammalian counterparts (Eichinger, L et al. 2005 ; Muller-Tauberger, A et al. 2013). A few examples of such processes may include heterotrimeric $G$ protein activation by GPCR, small GTPases Ras and Rac regulating signaling pathways, PI3K/Akt signaling pathway, regulation of PLC, STAT regulating pathway, regulatory pathways that modulate Arp2/3-dependent F-Actin and remodeling, Formin-dependent MyosinII/Cortexillin containing anti-parallel F-Actin filaments dynamics.

The phagocytosis in the mammalian system is a PIP2 dependent wasp Arp2/3 mediated F-actin branched synthesis. The involvement of phosphoinositides has been well characterized in the mammalian system. The interconversion of PIP2 to PIP3 by 
phosphorylation and de-phosphorylation has a central role in the phagocytosis initiation, phagosome closure and the Phagosome formation. The binding of the particle/pathogen to the cell surface receptors causes the extension of the membrane ruffles, this is facilitated by the branching of F-actin. At the binding of particle, there is enrichment of PIP2 at the membrane causing the membrane ruffles to extend and followed by enrichment of PIP3. This step repeats during the phagosome sealing where PIP2 is enriched on the membrane at the beginning of the phagosome sealing and is followed by PIP3 leading to the formation of a mature phagosome. As mentioned before, PIP2 facilitates the F-actin branching through WASP Arp2/3 pathway, whereas on phosphorylation of PIP2 to either PIP3 or PIP4 causes the degradation of the F-actin branching. PIP2 inhibits the capping proteins which avoids the formation of actin branches and inhibits the actin severing protein called cofilin (Figure 1). The actin filaments are degraded when the PIP2 levels are depleted by PI3 kinase, an enzyme which phosphorylates PIP2 to PIP3. The depletion of PIP2 causes the elevation of capping proteins and cofilin which results in the degradation of F-actin filaments and thus completing the process of the phagosome formation. While the role of PIP3 in phagocytosis is well defined in the mammalian system, but Dictyostelium PIP3 is shown to be involved only in micropinocytosis and not phagocytosis 


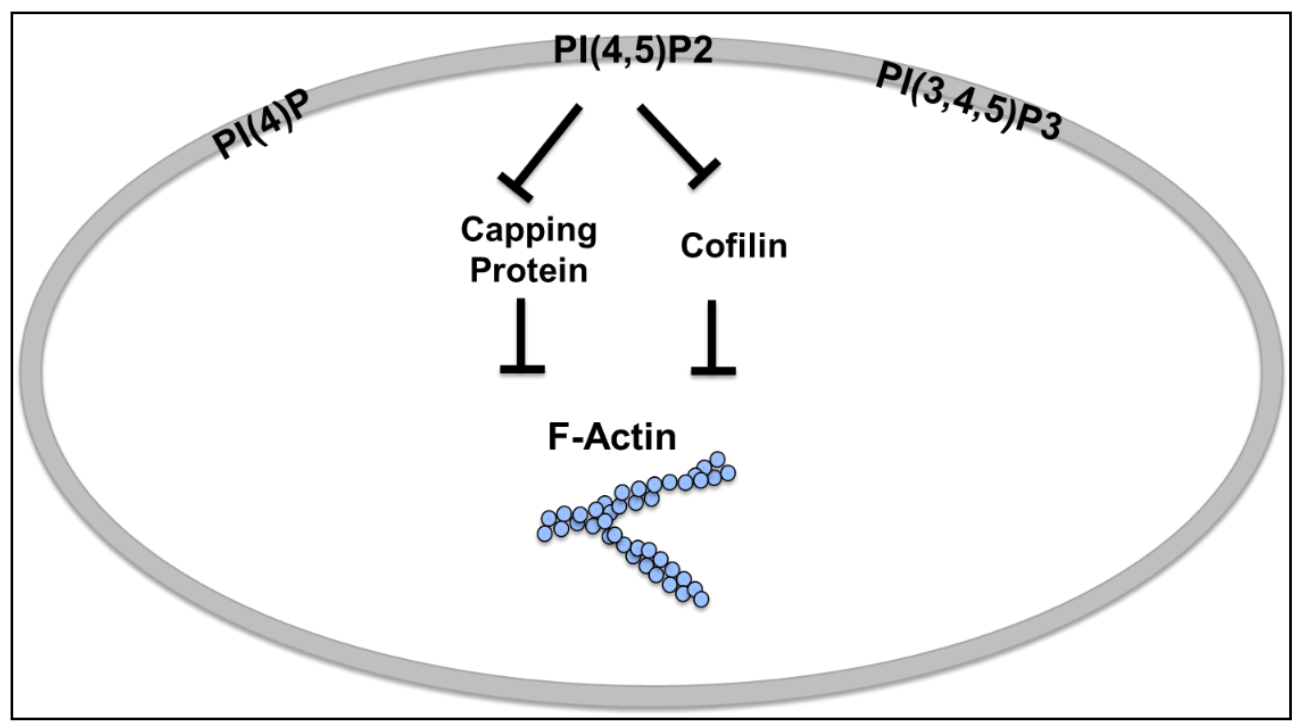

\section{FIGURE 1 REGULATION OF ACTIN BY PIP2}

Schematic representation of the regulation of F-actin in mammalian phagocytosis. PIP2 inhibits the actin capping protein which inhibits F-actin nucleation by capping them and also inhibits cofilin which severs the actin filaments. The phosphorylation of PIP2 to PIP3 by PI3 kinase depletes the PIP2 levels causing the increase of actin inhibiting proteins (cofilin, capping protein) which leads to the degradation of F-actin.

Dictyostelium is free-living single amoeba in growing (vegetative) stages, engulfing bacteria, yeast, and extracellular nutrients through phagocytosis and macropinocytosis through which Dictyostelium cells meet their growth requirement (Vogel, G et al. 1980; Eichinger, L et. al 2005; Muller-Tauberger,A et al. 2013). The rate of internalization of particle and fluid in Dictyostelium is significantly higher than the macrophages, neutrophils and dendritic cells. Decades of elegant studies uncovered that Dictyostelium and other higher eukaryotes operate these processes through highly conserved mechanisms. These together create a unique niche for Dictyostelium as an outstanding model organism to dissect the complicated nature of the regulatory circuits for phagocytosis and macropinocytosis. 
Furthermore the Dictyostelium genome was sequenced completely over a decade ago and is highly amenable for genetic manipulations because of the haploid nature of genome. Ectopic expression of almost any gene can easily be achieved either under constitutively active or inducible promoters. Proteins are often expressed with specific epi-tags for biochemical analysis or as a GFP-type of fusion protein for microscopic investigation, which will allow molecular level of study to determine the dynamics of subcellular localizations of a specific protein. In addition, the feasibility of generating gene knockout and knockdown strains has been a great advantage of using Dictyostelium as an organism. Lastly, Dictyostelium can be rapidly cultured in a large volume of suspension culture for biochemical analysis.

\subsection{Overall processes of Phagocytosis.}

Professional phagocytes are cells which exclusively perform phagocytosis for different reasons. Some of the professional phagocytes are the cells of the mammalian immune system and unicellular eukaryote Dictyostelium. In contrast to phagocytosis, macropinocytosis is not limited to these professional phagocytes and a number of pathogens can induce the process to get an entry into the host. Macropinocytosis is a constitutive process while phagocytosis is initiated when a particle is bound to the outer surface of the cell membrane, but phagocytosis is receptor mediated as mentioned earlier. In the mammalian system, phagocytosis begins with the binding of the particle to the receptor. There are a vast number of receptors that exist in the mammalian immune cells binding to different particles ranging from microbial pathogens to apoptotic cell debris. The binding of particles can be either direct or indirect in the mammalian system: particles can be indirectly bound to phagocytes when a particle is coated by an 
opsonizing molecule and presented and can be directly bound when specific receptors recognize molecular patterns like peptidoglycans, surface carbohydrates, and lipopolysaccharides present on the pathogen.

Several membrane proteins likely serve as phagocytic receptors in Dictyostelium. The involvement of distinguished receptors for Bacteria and latex beads was inferred by Hellio and Ryter (1980) after inhibition study using lectins. Vogel (1980) reported the existence of two types of receptors based on the experiments on a mutant Dictyostelium cell line that failed to ingest hydrophilic particles, but retained its phagocytic ability for bacteria. This experiment by Vogel et al. reported that a lectin type receptor interacts with the terminal glucose on the bacteria and a non-specific receptor triggers the uptake of the hydrophilic particles. Recent studies (Cornillon et al. 2008; Cornillon et al. 2006) have revealed a family of 5 proteins named SibA, SibB, SibC, SibD, and SibE that are related to the human beta-integrin could be the hydrophilic receptors previous described by Vogel et. al (1980). Cells with SibA ablation displayed a defect in phagocytosis of latex beads, but normal phagocytosis of bacteria.

Adhesion of the plasma membrane to a planar surface allows self-organizing FActin wave, which is heterotrimeric $\mathrm{G}$ protein and Arp2/3 regulator SCAR independent, and is a part of the autonomous tread-milling activity of F-Actin along the adhesion planes(Bretschneider et al. 2009; Ishikawa-Ankerhold et al. 2010). When the adhesion surface is not planar, self-organizing F-Actin wave simulates phagocytic cup structure beneath the particle adhesion site. This initial structure can proceed further by its rim extension and eventually a sealing event, but a number of regulatory singling modulate 
the process either positively or negatively. For example, the heterotrimeric G protein G $\square$ is not essential for the phagocytosis, but its ablation significantly decreased the efficiency of the process (Peracino et al., 1998).

Upon finalization of the phagocytic cup sealing, the early phagosome rapidly disassembles F-Actin at the cortical region, which is followed by small GTPase Rab7 recruitment. The Rab7 is proposed to control fusion of early phagosomes with a subset of lysosomes (Buczynski et al., 1997; Laurent et al., 1998; Rupper et al. 2001). A number of other Rab family members are also involved in along the complicated pathways of phagosome maturation (reviewed in Bozzaro et al., 2008).

\subsection{Phagocytosis requires specific cortical F-Actin remodeling activity}

In earlier studies, phalloidin was used to determine if F- actin is involved in the phagosome formation (Maniak et al. 1995). Phalloidin is a fluorescent molecule that binds to the F-Actin. When phalloidin was used to visualize F-actin, it was noticed that F-Actin accumulates below the nascent phagocytic cup. The use of actin nucleation interfering drugs such as Latrunculin and Cytochalasin decreased phagocytosis and macropinocytosis in Dictyostelium(Rupper et al. 2001; Loover et al. 1997). Different proteins that regulate the actin cytoskeleton were studied in recent times to look the spatial and temporal regulation of actin filaments, the signaling pathways leading to the actin reorganization in these two processes.

F-Actin synthesis of both mammalian cells and Dictyostelium depends on the assembly of Actin nucleation factors (either Arp2/3 complex or Formin), of which activities will be enhanced by signal dependent regulatory proteins such as WASP, Scar/Wave and ENA-VASP which regulates the actin nucleating Arp2/3 complex and 
Formin (Ishikawa-Ankerhold et al. 2010). Upon activation by regulatory factors, the ARP 2/3 complex will generate branched web-like structure while the Formin stimulate antiparallel F-Actin cable often involving Myosin-II and Cortexillin .

Considering that the F-Actin structure supporting phagocytic cup will be likely a branched structure rather than linear, regulatory proteins facilitating such structure are expected to enhance particle uptake. The ablation of Scar/Wave resulted in decreased levels of F-actin cell content and defective phagocytosis and macropinocytosis (Seastone et. al., 2001), but the disruption of Formin had no major effect on phagocytosis. Cells lacking Vasp displayed compromised particle adhesion, but no major defect in phagocytosis was observed (Han et al. 2002).

While the nucleating factors affect F-actin dynamics in phagocytosis and macropinocytosis, there are variety of other actin binding proteins regulating fragmentation, bundling and cross linking of the actin filaments could also modulate phagocytosis and macropinocytosis. ABP120 is an actin crosslinking protein stimulating web like F-Actin structure, which is enriched on the phagocytic cup. The abp120-null cells have displayed a decreased rate of particle uptake (Konzok et al. 1999). Coronin is another F-Actin associating protein that localizes to the phagocytic cup formation. Upon internalization, Coronin rapidly dissociates (within $1 \mathrm{~min}$ ) from the phagosome. Ablation of Coronin exhibited compromised phagocytosis as expected (Maniak, Rauchenberger, Albrecht, Murphy \& Gerisch (1995) ). AIP1 regulates cofilin, which is an F-actin destabilizing protein and localizes at the phagocytic cup and induces membrane ruffles. aip1-null mutants show a defect in phagocytosis and AIP1 over-expression enhanced the rate of phagocytosis (Konzok et al., 1999). Depleting cofilin is lethal to the cell, whereas 
cofilin overexpression did not change the rate of phagocytosis or macropinocytosis (Aizawa et al. 1996).

Recent studies uncovered that F-Actin remidleing is not always top-down type signaling event. Self-activating F-Actin structures occur in multiple occasions and cell types that encompasses from Dictyostelium to mammalian cells (Allard et al., 2012). Several studies uncovered that one type of this self-activating F-Actin structures is involved in the early event of phagocytosis (Bretschneider et al. 2009, Gerisch et al. 2010). According to this view, the base of the phagocytic cup is enriched with the Arp $2 / 3$ initiated dendritic F-Actin structure, while the outer region is enriched with Cortexillin/Myosin-II enriched bundled F-Actin structure (Gerisch et al. 2010). Interestingly, the dendritic region displayed higher level of PIP3 than the bundled FActin region. The involvement of phosphoinositides in the regulation of phagocytosis will be discussed later in this report.

\subsection{Regulatory circuits that fine-tune the process of particle uptake.}

As mentioned earlier, particle adhesion could cause phagocytic cup formation, but its progression is not always efficient process. Often a number of signaling components are involved in the fine-tuning of the process. These regulators not only encourage phagocytosis, but can also suppress the process.

Proteins that affect adhesion are highly expected to affect phagocytosis. Examples of such proteins include sibA (Cornillon et al., 2006), sibC (Cornillon et al., 2008), sadA (Fey et al. 2002, Froquet et al. 2012), and phg1A (Gebbi 2004) Talin A (Gebbie et al. 2004, Niewohner et al. 1997). Interestingly, PaxB, a Paxillin homolog, negatively regulate phagocytosis while facilitating cell adhesion (Priibic et al., 2011). 
Regulatory proteins that modify F-Actin dynamics are also highly expected group of proteins that would likely affect phagocytosis. The major F-Actin nucleating factor Formin and Scar, an activator of Arp2/3 nucleating factor, are reported to be a stimulatory factor for particle uptake (Seastone, et al., 2001, Winterhoff, et al., 2013). In addition, Coronin A, an actin binding protein regulating actin nucleation, plays a positive role in phagocytosis (Maniak, et al., 1995).

In addition to these organizers, Actin binding proteins such as ABP-C and ABPE1, ABPE-2, and AIP1 also positively contribute particle uptake (Rivero, et al., 1996, Dieckmann, et al., 2010, Konzok, et al., 1999). A number of type I Myosin affect phagocytosis either positively (MyoB, MyoC, MyoD, and MyoI) ( Jung \& Hammer 1990, Jung, Wu \& Hammer 1996, Titus 1999, Gebbie, 2004, Tuxworth 2001, Galdeen 2007) or negatively (MyoK and MyoE, Dieckmann 2010, Durrwang, 2006). Cortexillin, an actinbundling protein of the alpha-actinin/spectrin superfamily, and ElmoA, a Myosin II associating protein, are also negatively regulating phagocytosis (Liu 2014, Isik, 2008). It is interesting that Myosin II localizes at the base of the phagocytic cup, but cells lacking Myosin II do not exhibit aberrant phagocytosis, and that PakA, while colocalize with Myosin II at the base of the phagocytic cup, stimulates particle uptake activity (MullerTaubenberger, et al., 2002).

In addition to these cytoskeletal remodeling proteins, the heterotrimeric $\mathrm{G}$ protein and several small GTPases and their regulators are also reported to function positively. Some of these small GTPases and their rugulators include RasS, RapA, RacG, RacH, and RasGefB, ArfGef protein sec7, and GpbA the beta subunit of (Wilkins 2000,King \& Insall 2003, Peracino 1998, Sultana, 2009, Blanc 2005, Kang 2002, Seastone 
1999,Somesh 2006, Muller 2013). The potential downstream effector of RasS and Rap1 is Phg2. Phg2 is a serine/threonine kinase with Ras Binding Domain, to which RasS, RasG, and RapA bind.

The Rho family member Rac proteins have been demonstrated to affect the particle uptake and fluid uptake in Dictyostelium. Overexpression of Rac resulted in the increase of particle uptake. RacC protein interacts with Scar and regulates phagocytosis and DAG binding protein is required in RacC mediated phagocytosis. In one of the studies, it was seen that RacF1 is localized and enriched in the phagocytic cups and macropinocytic vesicles, but ablation of RacF1 had no effect on any of the actin dependent processes (Rivero et al. 1999). A dominant negative form of RacB showed a defect in phagocytosis and characterized by the presence of surface blebs (Lee et al. 2003).

Another small GTPase that affects negatively on particle uptake include Rheb, which is an upstream activator of TorC2 complex (Rosel, D , 2012). Consistent with this, TorC2 downstream target PKBA suppresses the particle uptake. It is, however, puzzling that the PKBA downstream target PakA suppresses phagocytosis instead of activating, especially considering its subcellular localizations include the base of phagocytic cup. Further research will be necessary to understand the role of PakA in the context of phagocytosis.

Downstream to the $\mathrm{G}$ proteins are membrane lipids generated by phospholipase, PI3 kinases and phosphatases. Phosphoinositides such as PIP2 and PIP3 have been known to play an important role in the regulation of actin cytoskeleton and membrane trafficking in the mammalian cells. In the mammalian system, PIP2 and PIP3 are known 
to aid the recruitment and de-nucleation of F-actin filaments in the initiation and the at the phagosome closure step. PIP2 is enriched in the initial formation of the phagocytic cup promoting the branched F-actin synthesis, while PIP3 is localized in the phagosome closure step promoting the F-actin degradation, thus completing the phagosome sealing (Levine et al., 2015). In the Dictyostelium cells, $11 \%$ of the total lipids in plasma membrane and endolysosomal membranes are phosphoinositides (REF). PIP2 is the target of PI3 kinase and PLC. Use of inhibitors of PLC and intracellular calcium chelators resulted in the significant inhibition of phagocytosis, while PI3 kinase inhibitors did not affect the bacterial uptake, rather fluid uptake was significantly affected after treatment with PI3K inhibitors (Seastone et al.,1999). In another study, contrasting results were shown where the PI3K inhibitors resulted in the inhibition of bacterial uptake (Dormann et al., 2004). In the same study they showed that, PTEN disruption resulted in no defect in bacterial uptake while there was some defect in yeast phagocytosis. However, recent studies on self-activating F-Actin structures, as mentioned earlier, underscored that PIP3 is accumulating at the region of dendritic F-Actin structure supporting phagocytic cup formation. Another study demonstrated that Dictyostelium cells lacking the whole six PI3K genes are still capable of phagocytose E. coli. (Peracino et al., 2010). More detailed analysis of particle uptake and the dynamics of self-activating F-Actin structure of this mutant will be very informative about the role of phosphoinositides in these processes.

The process of phagocytosis is a complex process involving different steps and multiple proteins as discussed in this chapter. A summary of the proteins involved, their effect on phagocytosis and macropinocytosis is compiled in the below table. 


\begin{tabular}{|c|c|c|c|}
\hline Gene name & Phagocytosis & Macropinocytosis & Reference \\
\hline abpA | abpC & Positive & No effect & (Han et al. 2002) \\
\hline aip1 & Positive & Positive & $\begin{array}{l}\text { (Ishikawa-Ankerhold et al. } \\
\text { 2010) }\end{array}$ \\
\hline Actin & Positive & Positive & (Gerisch et al. 2009) \\
\hline Clathrin & No effect & Positive & (O’Halloran \& Anderson 1992) \\
\hline Coronin & Positive & Positive & (Maniak et al. 1995) \\
\hline G及 Protein & Positive & No effect & (Peracino et al. 1998) \\
\hline LmpA & Negative & Positive & (Temesvari et al. 2000) \\
\hline MYO B,C & Positive & Positive & (Dürrwang et al. 2006) \\
\hline Myo VII & Positive & Positive & (Clarke et al. 2010) \\
\hline PakA & Positive & No effect & (Rupper \& Cardelli 2001) \\
\hline PI3 kinase & No effect & Positive & (Rupper \& Cardelli 2001) \\
\hline Phg1 & Positive & No effect & (Cornillon et al. 2000) \\
\hline PKB & Negative & Positive & (Rosel et al. 2012) \\
\hline PLC & Positive & No effect & (Loovers et al. 2007) \\
\hline
\end{tabular}




\begin{tabular}{|c|c|c|c|}
\hline Profilin & Negative & Positive & (Temesvari et al. 2000) \\
\hline RabB & Positive & No effect & (Bush et al. 1994) \\
\hline RAB7 & Positive & Positive & (Rupper et al. 2001) \\
\hline Rac1 & Positive & Positive & (Castellano et al. 2000) \\
\hline RacB & Positive & No effect & (Lee et al. 2003) \\
\hline RacC & Positive & No effect & (Seastone et al. 1998) \\
\hline Rap1 & Positive & Negative & (Lafuente et al. 2004) \\
\hline RasS & Positive & Positive & (Wilkins et al. 2000) \\
\hline Rheb & Negative & No effect & (Rosel et al. 2012) \\
\hline Scar & Positive & Positive & (Vlahou \& Rivero 2006) \\
\hline SibA & Positive & No effect & (Cornillon et al. 2008)\ \\
\hline Talin & Positive & No effect & (Niewöhner et al. 1997) \\
\hline TorC2 & Negative & No effect & (Rosel et al. 2012) \\
\hline Tsc1/2 & Positive & No effect & (Rosel et al. 2012) \\
\hline V-ATPase & Positive & Positive & (Temesvari et al. 1996) \\
\hline
\end{tabular}

Table 1 The above genes encode the specific protein which have either a positive effect or negative effect on the process of phagocytosis and micropinocytosis. The above 
experiment results are either from over expression studies, null mutants or using specific drugs which affects the protein expression.

- There have been several proteins involved in the process of phagocytosis and macropinocytosis, but the pathways involved are not well defined and there could be more possible proteins involved in the process of phagocytosis.

In this report, we tried to look at some of the proteins which have been previously implicated in other different cellular events. Ras proteins have been major regulators of chemotaxis. TorC2 has been known to inhibit phagocytosis from a previous study (Rosel et. al. , 2012). TorC2 has been also known to regulate chemotaxis which is also a F-actin dependent process. TorC2 activates PKBR1 and PKBA which further phosphorylate the PKB substrates. PKB substrate are a set of different proteins which on activation triggers the F-actin branch synthesis. Only one type of Ras has been studied so far in phagocytosis process, RasS. Dictyostelium has 12 different types of Ras GTPases discovered so far and out of these RasC and RasG have been majorly implicated in chemotaxis. In this report, I looked at effect of phagocytosis on different Ras knock out cell lines. PKB substrate have been known to regulate F-actin synthesis in chemotaxis, I n this report I also studied how phagocytosis affects the phosphorylations of PKB substrate. Further I studied the effect of the serine/threonine phosphatase PP2A/B56. B56 is the regulatory sub unit of PP2A phosphatase and it is coded by the gene PsrA. PsrA ablated cells previously showed aberrant phosphorylation of PKB proteins, elevated levels of PKBR1 and PKBA proteins (Rodriguez M. et. al , 2015) when stimulated with cAMP. 
Chemotaxis was defective in $p s r A-$. As chemotaxis is a F-actin dependent process, it was interesting to look at what would be the effects of psrA ablation on phagocytosis. Futhermore I studied a serine threonine kinase LKB1, which has been known to regulate cell stress and cell development. LKB1 has been known to be upstream of TorC1 in the mammalian system and regulates TSC1/TSC2. TSC1/TSC2 regulates Rheb which regulates phagocytosis. LKB1 being upstream to these pathways makes it a candidate protein to be studied on the process of phagocytosis. In this study we deciphered how LKB1 could be affecting phagocytosis.

\subsection{Reference}

Angelica, M. D., \& Fong, Y. (2008). NIH Public Access. October, 141(4), 520-529.

Bosgraaf, L., \& van Haastert, P. J. M. (2006). The regulation of myosin II in Dictyostelium. European Journal of Cell Biology, 85(9-10), 969-979.

Bretschneider, T., Anderson, K., Ecke, M., Muuller-Taubenberger, A., Schroth-Diez, B., Ishikawa-Ankerhold, H. C., \& Gerisch, G. (2009). The three-dimensional dynamics of actin waves, a model of cytoskeletal self-organization. Biophysical Journal, 96(7), 28882900.

Bush, J., Nolta, K., Rodriguez-Paris, J., Kaufmann, N., O’Halloran, T., Ruscetti, Cardelli, J. (1994). A Rab4-like GTPase in Dictyostelium discoideum colocalizes with $\mathrm{V}-\mathrm{H}(+)$-ATPases in reticular membranes of the contractile vacuole complex and in lysosomes. Journal of Cell Science, 107 ( Pt 1, 2801-2812.

Cornillon, S., Froquet, R., \& Cosson, P. (2008). Involvement of sib proteins in the regulation of cellular adhesion in Dictyostelium discoideum. Eukaryotic Cell, 7(9), 16001605.

Cornillon, S., Gebbie, L., Benghezal, M., Nair, P., Keller, S., Wehrle-Haller, B., ... Cosson, P. (2006). An adhesion molecule in free-living Dictyostelium amoebae with integrin beta features. EMBO Reports, 7(6), 617-21. 
Eichinger L, Lee SS, Schleicher M . (1999). Dictyostelium as Model System for Studies of the Actin Cytoskeleton by Molecular Genetics. Microscopy Research and Technique, 134(May), 124-134.

Dürrwang, U., Fujita-Becker, S., Erent, M., Kull, F. J., Tsiavaliaris, G., Geeves, M. a, \& Manstein, D. J. (2006). Dictyostelium myosin-IE is a fast molecular motor involved in phagocytosis. Journal of Cell Science, 119(Pt 3), 550-558. http://doi.org/10.1242/jcs.02774

Fallis, A. . (2013). No Title No Title. Journal of Chemical Information and Modeling, 53(9), 1689-1699.

Gerisch, G., Ecke, M., Schroth-Diez, B., Gerwig, S., Engel, U., Maddera, L., \& Clarke, M. (2009). Self-organizing actin waves as planar phagocytic cup structures. Cell Adhesion and Migration, 3(4), 373-382.

Haas, A. (2007). The phagosome: Compartment with a license to kill. Traffic, 8(4), 311-330.

Han, Y. H., Chung, C. Y., Wessels, D., Stephens, S., Titus, M. A., Soll, D. R., \& Firtel, R. A. (2002). Requirement of a vasodilator-stimulated phosphoprotein family member for cell adhesion, the formation of filopodia, and chemotaxis in Dictyostelium. Journal of Biological Chemistry, 277(51), 49877-49887.

Ishikawa-Ankerhold, H. C., Gerisch, G., \& Muller-Taubenberger, A. (2010). Genetic evidence for concerted control of actin dynamics in cytokinesis, endocytic traffic, and cell motility by coronin and Aip1. Cytoskeleton, 67(7), 442-455.

King, J., \& Insall, R. H. (2003). Parasexual genetics of Dictyostelium gene disruptions : identification of a ras pathway using diploids. BMC Genetics, 14(1987), 114.

Konzok, A., Weber, I., Simmeth, E., Hacker, U., Maniak, M., \& Müller-taubenberger, A. (1999). DAip1, a, 146(2), 453-464.

Lee, E., Seastone, D. J., Harris, E., Cardelli, J. A., \& Knecht, D. A. (2003). RacB regulates cytoskeletal function in Dictyostelium spp. Eukaryotic Cell, 2(3), 474-485.

Loovers, H. M., Kortholt, A., de Groote, H., Whitty, L., Nussbaum, R. L., \& van Haastert, P. J. M. (2007). Regulation of phagocytosis in Dictyostelium by the inositol 5phosphatase OCRL homolog Dd5P4. Traffic, 8(5), 618-628.

Maniak, M., Rauchenberger, R., Albrecht, R., Murphy, J., \& Gerisch, G. (1995). Coronin involved in phagocytosis: Dynamics of particle-induced relocalization visualized by a green fluorescent protein tag. Cell, 83(6), 915-924. 
Mayinger, P. (2012). Phosphoinositides and vesicular membrane traffic. Biochimica et Biophysica Acta - Molecular and Cell Biology of Lipids, 1821(8), 1104-1113.

Müller-Taubenberger, A., Bretschneider, T., Faix, J., Konzok, A., Simmeth, E., \& Weber, I. (2002). Differential localization of the Dictyostelium kinase DPAKa during cytokinesis and cell migration. Journal of Muscle Research and Cell Motility, 23(7-8), $751-763$.

Nolta, K. V, Padh, H., \& Steck, T. L. (1991). Acidosomes from Dictyostelium. J. Biol. Chem., 266, 18318-18323.

Peracino, B., Borleis, J., Jin, T., Westphal, M., Schwartz, J. M., Wu, L., ... Bozzaro, S. (1998). G protein $\beta$ subunit-null mutants are impaired in phagocytosis and chemotaxis due to inappropriate regulation of the actin cytoskeleton. Journal of Cell Biology, 141(7), $1529-1537$.

Rebstein, P. J., Cardelli, J., Weeks, G., \& Spiegelman, G. B. (1997). Mutational analysis of the role of Rap1 in regulating cytoskeletal function in Dictyostelium. Experimental Cell Research, 231(2), 276-83.

Rivero, F., Albrecht, R., Dislich, H., Bracco, E., Graciotti, L., Bozzaro, S., \& Noegel, A. A. (1999). RacF1, a novel member of the Rho protein family in Dictyostelium discoideum, associates transiently with cell contact areas, macropinosomes, and phagosomes. Molecular Biology of the Cell, 10(4), 1205-19.

Rosel, D., Khurana, T., Majithia, A., Huang, X., Bhandari, R., \& Kimmel, A. R. (2012). TOR complex 2 (TORC2) in Dictyostelium suppresses phagocytic nutrient capture independently of TORC1-mediated nutrient sensing. Journal of Cell Science, 125(Pt 1), 37-48.

Rupper, a, Lee, K., Knecht, D., \& Cardelli, J. (2001). Sequential activities of phosphoinositide 3-kinase, PKB/Aakt, and Rab7 during macropinosome formation in Dictyostelium. Molecular Biology of the Cell, 12(9), 2813-2824.

Sallusto, B. F., \& Lanzavecchia, A. (1994). From the "Basel Institute for Immunology, CH-4005, Basel, Switzerland; and the *Department of Immunology, Istituto Superiore di SanitY, 1-00161, Rome, Italy. Journal of Experimental Medicine, 179(April).

Scott, C. C., Dobson, W., Botelho, R. J., Coady-Osberg, N., Chavrier, P., Knecht, D. Grinstein, S. (2005). Phosphatidylinositol-4, 5-bisphosphate hydrolysis directs actin remodeling during phagocytosis. Journal of Cell Biology, 169(1), 139-149.

Stuart, L. M., \& Ezekowitz, R. A. B. (2005). Phagocytosis: Elegant complexity. Immunity, 22(5), 539-550. 
Thelen, M., \& Didichenko, S. A. (1997). G-protein coupled receptor-mediated activation of PI 3-kinase in neutrophils. Annals of the New York Academy of Sciences, $832,368-382$.

Temesvari, L. a, Rodriguez-Paris, J. M., Bush, J. M., Zhang, L., \& Cardelli, J. a. (1996). Involvement of the vacuolar proton-translocating ATPase in multiple steps of the endo-lysosomal system and in the contractile vacuole system of Dictyostelium discoideum. Journal of Cell Science, 109 ( Pt 6, 1479-1495.

Vogel, G., Thilo, L., Schwarz, H., \& Steinhart, R. (1980). Mechanism of phagocytosis in Dictyostelium discoideum: Phagocytosis is mediated by different recognition sites as disclosed by mutants with altered phagocytotic properties. Journal of Cell Biology, 86(2), 456-465.

Wilkins, A., Chubb, J. R., \& Insall, R. H. (2000). A novel Dictyostelium RasGEF is required for normal endocytosis, cell motility and multicellular development. Current Biology, 10(22), 1427-1437. 


\section{CHAPTER 2. THE ROLE OF PKB SUBSTRATE PHOSPHORYLATION IN PHAGOCYTOSIS AND REGULATION OF THE PARTICLE UPTAKE BY PP2A/B56 SUBUNIT.}

\subsection{Summary}

The involvements of the phosphoinositides in the process of phagocytosis have been reported previously by several studies, but the molecular nature of phosphoinositide-mediated regulation of phagocytosis remains elusive. Studies on the mechanism of eukaryotic chemotaxis uncovered that PKBs plays critical role in remodeling dendritic F-Actin remodeling at the leading edge of a migrating cell, but the role of PKBs in the context of phagocytosis remains to be elucidated. The current study, for the first time, uncovered that PKB plays critical role in the regulation of phagocytosis through phosphorylation of PKB substrates. Furthermore, we also discovered that PP2A/B56, a negative regulator of PKBs, heavily affect phagocytosis, which is consistent with our previous report showing that cells lacking B56 suffer higher levels of PKBs activity. PKB substrate phosphorylation changes during the phagocytosis and the effects of LY249002, which is an inhibitor of PI3K upstream activator of PKB, on phagocytosis of wild type, $p s r A^{-}$, and $L K B 1-R N A i$ cells were determined in this study.

\subsection{Introduction}

Dictyostelium discoideum is a soil dwelling amoeba of which growth depends on the particle and fluid uptake through phagocytosis and macropinocytosis . Dictyostelium cells often encounter bacteria and yeast and are capable of internalize these food source through (Vogel et al. 1980). Phagocytosis is the characteristic of the cells of immunity in

mammalian system like Neutrophils and Macrophages. These cells provide the first line of defense in the mammalian system and engulf the foreign particles through 
phagocytosis. Reports from several groups over decades has unveiled the mechanism of phagocytosis however, the realization that phagocytosis is a consequence of complex processes involving different receptors and regulatory signaling networks, invites further investigation to uncover the regulatory circuits for the phagocytosis.

Previous studies on the regulation of PKBs and F-Actin remodeling during chemotaxis provides mechanical insight on the phagocytosis, which is also a F-Actin remodeling driven process synonymous to chemotaxis (Cai et al. 2010; Scott et al. 2005). Dictyostelium cells facing chemoattractant gradient persistently activate certain Ras protein at the leading edge, where one of Ras downstream targets PI3K persistently generate PIP3 (Cai et al. 2010). The other Ras downstream target TorC2, together with another upstream activator PDK1/2, activate PKBs . Upon activation by these upstream activator, PKBs phosphorylate multiple targets, which in turn induces proper remodeling of dendritic F-Actin structures such as lamellipodia and pseudopodia (Cai et al. 2010). Other regions of a migrating cell exhibit enrichment of F-Actin bundles organized in an antiparallel manner with actin binding proteins such as Myosin II, PakA, Cortexillin, and the actin-binding domain of TalinA (Konzok et al. 1999).

Thus there exist a number of similar events are shared by phagocytosis and chemotaxis, but each process has its own idiosyncratic aspect. First of all, in migrating cells, Myosin II, PakA, Talin A are excluded in the leading edge where dendritic F-Actin structures such as lamellipodia and pseudopods dominate but accumulate at the rear end where F-Actin bundles mediate contraction and Talin A adhesion (Cornillon et al. 2006; Müller-Taubenberger et al. 2002). However, when cells are up taking particles, Myosin II 
and PakA localize to the dendritic F-Actin enriched base of the phagocytic cup, in which the actin-binding fragment of Talin A also accumulate (Weber et al., 2002, MullerTaubenberger, 2002). Cells engaged in the process of particle up take also display dendritic F-actin enriched phagocytic cup and bundled F-Actin rich cortexes outside the phagocytic region, but the localizations of these critical regulatory components do not coincide with the dichotomy on the basis the type of F-Actin structure (Rivero et al. 1996). Thus nurturing a proper type of gross F-Actin organization seems to be necessary, but not sufficient to define a specific type of F-Actin driven events such as Chemotaxis and Phagocytosis.

The adhesion of particles to the cell surface receptor induces the activation of different of reactions as described in the previous chapter. Self-activating F-Actin waves is a constitutive activity that requires positive regulatory input to solidify the initial adhesion between the particle and the host cells. One of the processes potentially involved in this early step would be the heterotrimeric G $\beta$ activation, of which ablation decreased the efficiency of the phagocytosis (Peracino et al. 1998). Upon activation of G $\beta$ protein, the GDP bound Ras proteins exchange GDP to GTP through the function of RasGef proteins. Surprisingly, only RasS, among the twelve Dictyostelium Ras proteins, is reported to affect phagocytosis (Wilkins et al. 2000). In contrast, multiple Ras proteins such as RasG, RasC, RasB, and Rap1, are known to regulate chemotaxis. Theoretically, RasC and RasG could affect phagocytosis through regulating PKBs and RasB and Rap1 through Myosin II. RasG, RasS, and Rap1 could modulate phagocytosis through regulating serine/threonine kinase Phg2, which contains Ras Binding Domain that binds 
to RasG, RasS, Phg2 (Rebstein et al. 1997). Cells lacking Phg2 displayed sever phagocytic defects (Blanc, et al., 2005, Gebbie, et al., 2004).

In a recent study, ablation of PsrA, which codes the B56 subunit of the PP2A phosphatase complex, resulted in aberrantly high activity of PKBs and also an aberrantly high phosphorylation of PKB substrates. PP2A is a serine/threonine phosphatase system that is comprised of a catalytic subunit $\mathrm{C}$, a scaffolding subunit $\mathrm{A}$, and a large number of regulatory subunit B. The B subunit is a family if protein that include B, B'(B56), and B'. Among these subclasses of the B subunit, B56 is known to affect multiple cellular processes such as the canonical Wnt pathway, metazoan development, and tumorigenesis. The Dictyostelium B56 is known to affect GSK3 function during cell differentiation and PKBs during chemotaxis (Lee et al., 2008, Pino et al., 2015). It was suggested that PP2A/B56 is likely suppress PKBs upstream activators such as TorC2 and/or PDK1/2, but not Ras small GTPases (Pino et al., 2015). An independent study uncovered that TorC2 suppresses phagocytosis in a PKB independent mechanism (Rosel et al., 2012).

In this chapter, we describe the involvement of PKB substrate phosphorylation in the process of phagocytosis and we uncovered that the process of phagocytosis accompanies PKBs substrates phosphorylation. PKB substrates have been previously known to the driving factors of the chemotaxis and the aberrant regulation of PKB substrate phosphorylation causing a defect in chemotaxis. Chemotaxis being a F-actin dependent process reveals the importance of PKB substrate regulation. There were no studies previously reported about the involvement of PKB substrate in Phagocytosis, but we discovered how PKB substrates are involved in Phagocytosis . We also reported that 
$p s r A^{-}$cells are compromised in the process of particle uptake and PKB substrates phosphorylation was aberrantly high before and during the process of particle up take. $p s r A^{-}$cells, however, displayed normal rate of fluid phase up take and wild type level of adhesion to the substratum. Furthermore, a near complete restoration of particle uptake activity was observed when $p s r A^{-}$cells were treated with a PI3K inhibitor (LY294002

\subsection{Materials and Methods}

\subsubsection{Cell culture}

The different strains will be grown in D3T media (15.30 g Peptone \#3, $7.15 \mathrm{~g}$ of Yeast extract, $15.4 \mathrm{~g}$ Glucose, $0.48 \mathrm{~g} \mathrm{KH}_{2} \mathrm{PO}_{4}, 0.525 \mathrm{~g} \mathrm{Na}_{2} \mathrm{PO}_{4} .7 \mathrm{H}_{2} \mathrm{O}, \mathrm{H}_{2} \mathrm{O}$ to complete 1L). All strains were supplemented with $0.5 \mathrm{mg} / \mathrm{ml}$ thymidine (since all my cells and mutants were derived from the $J H 10$ wild type strain). Additionally, $5 \mathrm{ng} / \mu 1$ blasticidin were added to all transformants in the SodC background, and G418 $20 \mu \mathrm{g} / \mu 1$ to all Ras overexpressors.

Cells were kept in Nunc stationary culture flasks (Thermo scientific cat\# 136196) at 20 degrees Celsius. For most experimental purposes cells were grown in shaken suspension at $150 \mathrm{rpm}$ (Wats and Ashworth, 1970) to a density of $\sim 2.5 \times 10^{6}$ cells $/ \mathrm{mL}$. The cells number will be obtained using a hemocytometer. After this, cells will be harvested and used for the different experiments.

\subsubsection{Western blot}

Dictyostelium cells were harvested by centrifugation and were lysed with complete TTG ( $1 \%$ Triton, 5\% Glycerol, $0.15 \mathrm{M} \mathrm{NaCl}, 20 \mathrm{mM}$ TRIS HCl pH 7.7 , $1 \mathrm{mM}$ EDTA, 1mM sodium orthovanadate, $40 \mathrm{mM}$ ammonium molybdate, $1 \%$ BME, 1 table of protease inbitor/10 ml of TTG). $1 \mathrm{ml}$ of complete TTG was used to lyse 25 million cells. 
Protein lysates were mixed with 4x LDS sample loading buffer and boiled at $100^{\circ} \mathrm{C}$ for 3 minutes.

The cell lysates were fractionated by SDS-PAGE gel electrophoresis (Sambrook et al., 1989). The fractionated proteins were transferred on a nitrocellulose membrane and blocked with $2 \%$ Bovine serum albumin for 25 minutes. A suitable primary antibody was added, incubated overnight and a enzyme linked secondary antibody specific to the primary antibody was added and incubated for 3 hours. The bound secondary antibody was detected by chemiluminescence and thus normalized accordingly.

SDS-polyacrylamide gel electrophoresis was utilized to fractionate and normalize the proteins lysates. Proteins were transferred onto nitrocellulose membranes (Millipore) once the electrophoresis was done, blocked with a 2\% BSA (Amresco) for $30 \mathrm{~min}$ and probed overnight at 4 degrees $\mathrm{C}$ or 2 hours at room temperature using a suitable antibody. The bound antibody was detected by means of enhanced chemiluminescence (ECL, Cell Signaling Technology).

\subsubsection{Analysis of Phagocytosis using TRITC labelled yeast}

Cells in the log phase were pelleted in a table top centrifuge and re-suspended in media at a concentration of $2 \times 10^{6}$ cells $/ \mathrm{ml}$. TRITC beads were added at a concentration six fold to that of Dictyostelium cells. At different time intervals, $1 \mathrm{~mL}$ of the sample was withdrawn, added to $100 \mu \mathrm{L}$ of tryphan blue and incubated for $3 \mathrm{~min}$. The samples will be then centrifuged, re-suspended in Sorensen phosphate buffer $\left(2 \mathrm{~m} M \mathrm{Na}_{2} \mathrm{HPO}_{4}, 15 \mathrm{~m} M\right.$ $\mathrm{KH} 2 \mathrm{PO} 4, \mathrm{pH}$ 6.0) and the fluorescence was read in fluorimeter (Excitation $544 \mathrm{~nm}$; emission $574 \mathrm{~nm})$. 
For the PKB substrate phosphorylation, the cells were treated with yeast at different time points and lysed with $1 \mathrm{x}$ complete TTG at the concentration of $1 \mathrm{ml}$ per 25 million cells and the lysates were fractionated using SDS-PAGE and western blot was performed as described earlier. The nitrocellulose membrane from the western blot was treated with Phospho-Akt Substrate (RXXS*/T*) (110B7E) (cell signaling technologies).

\subsubsection{Pinocytosis Assay}

Cells in the log phase were pelleted in a table top centrifuge and re-suspended in media at a concentration $5 \times 10^{6}$ cells $/ \mathrm{ml}$. FITC dextran will be added at a concentration of $100 \mu \mathrm{L}$ for $5 \mathrm{~mL}$ of the cells suspended in media. $0.5 \mathrm{~mL}$ of the sample was drawn and added to $1.5 \mathrm{~mL}$ of ice cold Sorensen buffer ( $2 \mathrm{mM} \mathrm{Na}_{2} \mathrm{HPO}_{4}, 15 \mathrm{mM} \mathrm{KH} \mathrm{PO}_{4}, \mathrm{pH} 6.0$ ) and centrifuged. Further was washed once with Sorensen buffer, centrifuged and $1 \mathrm{ml}$ of lysis buffer ( $50 \mathrm{mM} \mathrm{Na}_{2} \mathrm{HPO}_{4}, \mathrm{pH} 9.4,0.2 \%$ triton $\left.\mathrm{X}-100\right)$ and the fluorescence will be measured using a fluorimeter (Excitation $470 \mathrm{~nm}$, Emission $515 \mathrm{~nm}$ ).

\subsubsection{Bacterial cell culture}

The E. coli bacterial cells were grown overnight in $100 \mathrm{ml}$ LB medium plus 50ug/mL ampicillin for about 16 hours at 37 degrees $C$ and $200 \mathrm{rpm}$. A stock of the cells containing the different plasmids was made in final $30 \%$ glycerol solution and stored at 80 degrees $\mathrm{C}$ for future use. After that, cells were pelleted using a IEC CL30R centrifuge at $4000 \mathrm{rpm}$ for 25 minutes. The DNA was obtained from the pellet using the Midi-Prep kit from Quiagen. After measuring optical density at $260 \mathrm{~nm}$ using the GENESYS 10uv spectrophotometer, the pellets were stored at -20 degrees $\mathrm{C}$ for future use. 


\subsubsection{Transfection}

Five million of Dictyostelium exponentially growing cells were centrifuged for 5 min at $2000 \mathrm{rpm}\left(4^{\circ} \mathrm{C}\right)$, washed once with $\mathrm{H}-50$ and resuspended in $100 \mu \mathrm{l}$ of $\mathrm{H}-50$. The cells were mixed with $10 \mu \mathrm{g}$ of desired DNA, and placed in a cold $0.1 \mathrm{~cm}$ Fisher electroporation cuvette (cat\# FB101). Electroporation will be done at $1 \mathrm{kV}$ two times with a pause of $5 \mathrm{sec}$ between pulses. Cells were placed in a ice for 5 minutes and then transferred into a $10 \mathrm{~cm}$ Petri dish with $10 \mathrm{ml}$ of D-3T media, supplemented with 0.5 $\mathrm{mg} / \mathrm{mL}$ thymidine. After $24 \mathrm{~h}, \mathrm{G} 418$ was added as a means of selection. This method was modified from Schauer et al., 1993.

\subsection{Results}

\subsubsection{Ras and PI3 kinase is involved in phagocytosis.}

Previous studies demonstrated that PI3Ks are involved in the fluid uptake and inhibition of PI3K activity significantly hampered macropinocytosis (Cardelli, 2001). It is, however, less than clear if PI3Ks are also involved in the phagocytosis. Contrasting results were reported from several independent studies using latex bead, bacteria, and yeast as a target particle for cells treated with PI3K inhibitor or cells lacking major PI3K activity (Peracino et al. 2010; Hoeller et al. 2013).

To gain further insight on this conundrum, GFP-PHcrac protein, a marker for $\mathrm{PI}(3,4,5) \mathrm{P} 3$, was expressed in wild type cells as described in the materials and methods. The GFP-PHcrac expressing cells were fed with TRITC-yeast and the excessive TRITCyeast outside the Dictyostelium host were quenched with trypan blue. Fluorescent images

of GFP-PHcrac and TRITC-yeast displayed co-localization only in the rim region of a phagocytic cup, but not when the yeast was internalized (Figure 2A). At least in our 
hands, $\mathrm{PI} 3 \mathrm{~K}$ product $\mathrm{PI}(3,4,5) \mathrm{P} 3$ localized to the rim region of a phagocytic cup, likely facilitating the rim extension.

In the absence of specific signal, the PI3K1 and PI3K2, the two kinases responsible for the majority of PI3K activity in Dictyostelium cells, localize at the cytoplasm . Upon receiving GPCR initiated singling, a yet to be defined membrane localization signal recruits PI3K to the plasma membrane in a F-Actin dependent manner. Another line of signaling events also activate Ras proteins and one of which in turn binds to the Ras Binding Domain (RBD) of the PI3K and thus shifts the conformation of PI3K into more active conformation. It is thus likely that the phagocytic accumulation of $\mathrm{PI}(3,4,5) \mathrm{P} 3$ is a consequence of active Ras localization to the phagocytic rim region. To confirm this hypothesis, GFP-RBD, a probe that detects active Ras protein, was expressed in wild type cells. Cells expressing GFP-RBD were fed with TRITC-yeast, and fluorescent images were captured. Similar to the case of PIP3, active Ras proteins were enriched at the rim of a phagocytic cup (Figure 1a). Although we could not specify the type of active Ras accumulated in the rim region of the phagocytic cup, active Ras proteins are likely involved in the stimulation of Rim extension accommodating branched F-Actin remodeling by regulating multiple down stream targets that not only include PI3K, but may also include PKB kinases and their substrates.

\subsubsection{PKB substrate phosphorylation levels increased during phagocytosis in wild type cells.}

When Dictyostelium cells are directionally migrating toward an external chemoattractant, persistent Ras activation accompanied with accumulation of PIP3 at the leading edge of the cell. The cortical region of the leading edge of a migrating cell 
packed with dendritic F-Actin structures nucleated by Arp2/3 complex. It is often assumed that PKB is modulating the remodeling of the lamellipodial F-Actin structure by phosphorylating multiple PKB substrates during the migration. Typical PKB substrates include TalinB (pp280), RasGefN (pp200/pp180), GacG(RhoGAP)/PakA (pp140), RasGefS/PI5K (pp110), and GacQ(RhoGAP, pp65). Among these, pp140 PakA was suggested to play a major role in linking upstream PKB signaling to the cytoskeletal remodeling (Tang et al., 2010).

Similarly, when a cell encounters a particle, the host plasma membrane remodels the cortical region from Myosin-II containing antiparallel bundled F-Actin to Arp2/3 initiated dendritic F-Actin structure which is enriched with PI(3,4,5)P3 (Gerisch PMC Biophysics 2010, 3:7).

Considering the similarity between the two events, certain Ras proteins enriched at the phagocytic cup may recruit and activate PKBs and thus induce PKB substrate phosphorylation. To this end, Dictyostelium cells were fed with yeast and whole cell lysates were prepared at 0,5 , and 20 minutes of feeding. The lysates were normalized by anti-Actin western blot, and the normalized lysates were analyzed with anti-phosphoPKB substrates antibody (Cell Signaling Technologies). As shown in Figure 2, there was clear increase in PKBs substrate phosphorylation after yeast uptake. At time zero, low level of basal phosphorylation of p280 and p180 was observed. A clear rise in the level of phosphorylation of $\mathrm{p} 350, \mathrm{p} 280,, \mathrm{p} 180, \mathrm{p} 140$, and $\mathrm{p} 110$ was clearly observed during the process of phagocytosis (Fig. 2B). Phosphorylation of TalinB (p280), RasGefN (p200/p180), and RasGefS/PI5K (p110) were rapid and intensive, but that of p350, the 
identity yet to be uncovered, was less dramatic and that of PakA (p140) was slow. The p67, GacQ (RhoGAP) phosphorylation was not clearly increased during phagocytosis. These results indicate that the majority of PKB substrates are phosphorylated during the process of phagocytosis, likely modulating dynamic dendritic F-Actin structure remodeling to cope with early phases of particle uptake. It was also clearly noticed that TalinB, RasGefN, and RasGefS/PI5K displayed a weak, yet clear basal level phosphorylation before the process of phagocytosis. We speculate that the self-activating Ras activity in cells exhibiting random motility may also engage PKB signaling to accommodate specific dendritic F-Actin remodeling to support pseudopod formation.

\subsection{3 ras $^{-}$cells have lower levels of phagocytosis and fluid uptake.}

Previous genetic studies indicated that RasS is involved in phagocytosis (Wilkins et al. 2000), but no report showed the other well-characterized Ras proteins that could modulate the F-actin remodeling are involved in the particle uptake. To determine if other Ras proteins are involved in phagocytosis, cells lacking these Ras proteins were investigated if they display defects in phagocytosis. RasG, RasC and RasD are the three extensively characterized Ras proteins Dictyostelium. Cells lacking RasG and RasD displayed wild type level of phagocytosis toward TRITC-yeast. In contrast, $\operatorname{ras} C^{-}$cells displayed $\sim 30 \%$ decrease in phagocytosis (Fig. 1B). The phagocytosis were quantitated by measuring internalized FITC fluorescence value divided by the total mass of host cells used for each assay as described in the Materials and Methods. 
Interestingly, $\mathrm{rasC}^{-}$cells were also defective in fluid uptake activity when measured by FITC-dextran as a fluid phase marker (Fig. 1C). ras ${ }^{-}$cells, in contrast, displayed no such aberrancy, suggesting RasC plays a distinct role in regulating the fluid uptake process. The total fluid phase uptake was quantitated by measuring internalized FITC fluorescence value divided by the total mass of cells used for each assay as described in the Materials and Methods. The compromised total fluid uptake activity in ras $C^{-}$cells was a surprise considering that RasC is not interacting with any of the five PI3K in Dictyostelium (Hoeller et al., 2013). Potential mechanisms that RasC affects fluid uptake will be described in the Discussion.

\subsection{4 $\mathrm{psr}^{-}$cells display severely compromised phagocytosis while Fluid uptake was unaffected.}

A previous study demonstrated that cells lacking PP2A/B56 ( $p s r A^{-}$cells) are defective in Ras activation but aberrantly high level of PKB activity in the context of chemotaxis (Pino et. al., 2015). Considering that phagocytosis is accompanied with PKB substrate phosphorylation as described earlier, we hypothesized that $p s r A^{-}$cells may experience dysregulation of particle uptake due to the misregulation of PKB signaling. $p s r A^{-}$cells in a growth phase were fed with TRITC-yeast and internalized fluorescence value was measured after quenching the excess TRITC yeast with Tryphan Blue. The phagocytosis efficiency was quantitated by total measuring internalized FITC fluorescence value divided by the total mass of host cells used for each assay as described in the Materials and Methods section. 60\% decrease in fluorescence was observed from $p s r A^{-}$cells compared to that of wild type (Fig. 3A). Fluorescent and phase contrast 
microscopic images taken at 30 min of phagocytosis also supported the observation that $p s r A^{-}$cells are severely compromised in the particle uptake (Fig. 3B).

Unlike $\mathrm{rasC}^{-}$cells, which were defective in both particle and fluid uptake processes, $p s r A^{-}$cells demonstrated wild type level of fluid uptake capability (Fig. 3C). The total fluid phase uptake was quantitated by measuring internalized FITC fluorescence value divided by the total mass of cells used for each assay as described in the Materials and Methods. It is interesting that $p s r A^{-}$exhibit only phagocytosis defect, but wild type level of fluid uptake activity.

\subsubsection{Treatment of psrA- cells with PI3 kinase inhibitor LY 249002 restored the phagocytosis.}

A recent study (Rosel et al., 2012) demonstrated that a small GTPase Rheb suppresses phagocytosis in a TorC 2 dependent, but PKB independent mechanism. One of the most critical point of the report was that activation of TorC2 by expression of constitutively active Rheb mutant suppressed particle uptake in the absence of PKB. Cells lacking PKBA, unlike cells lacking TorC2 components, displayed attenuated particle uptake upon expression of constitutively active Rheb mutant. Thus, both TorC2 and PKB can suppress particle uptake but through distinct mechanisms.

Given that $\mathrm{psrA}^{-}$cells display high levels of PKB activities, suppression of one of their upstream activator PI3K activity may improve the compromised particle uptake activity. To this end, wild type and $p s r A^{-}$cells were treated with PI3K inhibitor LY294002 and their phagocytic activity was quantitated using TRITC-yeast as described before. Previous studies showed that above certain concentrations, LY294002 could inhibit both PI3K and TorC2 activity (Pascale et al., 2012), and thus we determined the 
level of LY294002 that does not hamper the particle uptake activity of wild type cells. Figure 4A shows that treatment of wild type cells with $50 \square \mathrm{M}$ of LY 294002 induced no deleterious effect on phagocytosis in wild type cells. Under the same concentration of LY294002 treatment, $p s r A^{-}$cells significantly restored its particle uptake capability to the level of wild type cells. Considering that the main molecular phenotype of $\mathrm{psr}^{-}$cells is the high PKB activity, which can be a consequence of loss of a phosphatase that can directly dephosphorylate PKBs or loss of one that inhibit PKB upstream activators such as PDK1/2 or TorC2. The molecular nature of this LY294002 mediated restoration of particle uptake of $\mathrm{psr}^{-}$cells requires extensive future research, but would fit better for the latter possibility that PP2A/B56 are suppressing PKB upstream activators.

\subsubsection{PKB substrate phosphorylation pattern in $p \mathrm{~s}^{-}$cells were rectified similarly to those of the wild type upon treatment with LY294002 treatment.}

As described earlier, wild type cells display increased phosphorylation of PKBs substrates during the course of phagocytosis (Fig 2B). To determine the PKBs substrate phosphorylation pattern of $p s r A^{-}$cells during the course of particle uptake, $p s r A^{-}$cells were fed with yeast and whole cell lysates were prepared at 0,5 , and 20 minutes of yeast feeding. The lysates were normalized by anti-Actin western blot, and the normalized lysates were analyzed with anti-phospho-PKB substrates antibody (Fig. 5A). Consistent with high PKBs substrate phosphorylation of $p_{s} \mathrm{~A}^{-}$cells in the context of chemotaxis (Pino et al., 2015), $p s r A^{-}$cells also exhibited significantly high levels of PKBs substrate phosphorylation. p280 TalinB was most significantly hyper-phosphorylated, but all other reported PKBs substrates were also highly phosphorylated under growing stage $\mathrm{psr}^{-}$ cells, and the phosphorylation persisted during the course of particle uptake. 
Treatment of $p s r A^{-}$cells with LY294002 rectified phosphorylation pattern of PKBs substrates in $p s r A^{-}$cells similarly to those in wild type cells. p280 TalinB phosphorylation was clearly attenuated to the level of wild type. Although not all other PKBs substrate phosphorylation patterns are identical to those of wild type cells. Phosphorylation of p350 and p200/p180 RasGefN were still high in LY294002 treated psrA- cells compared to those in wild type cells, suggesting that dysregulation of TalinB phosphorylation is likely the major defect of particle uptake process in $p s r A^{-}$cells.

\subsection{Figures}

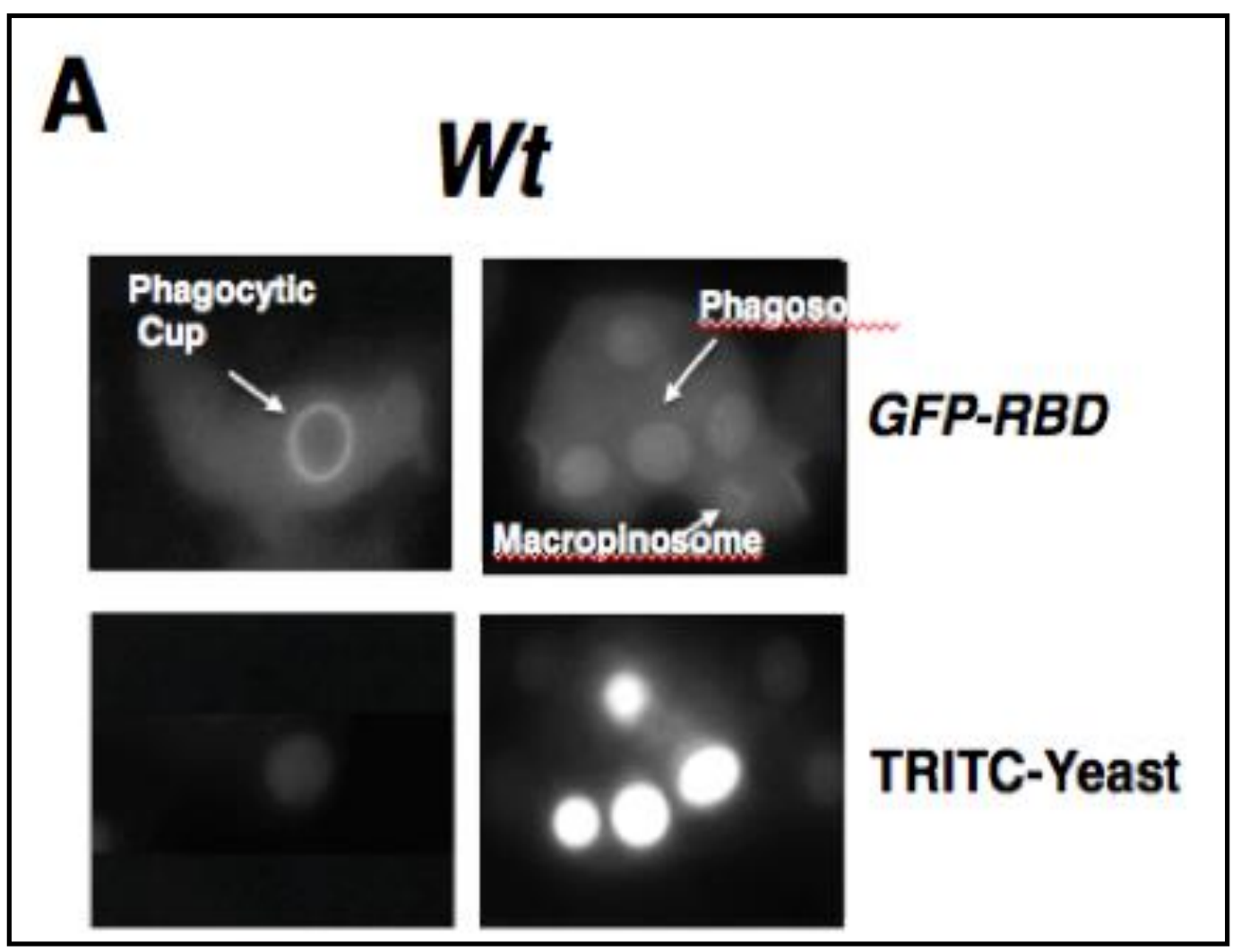




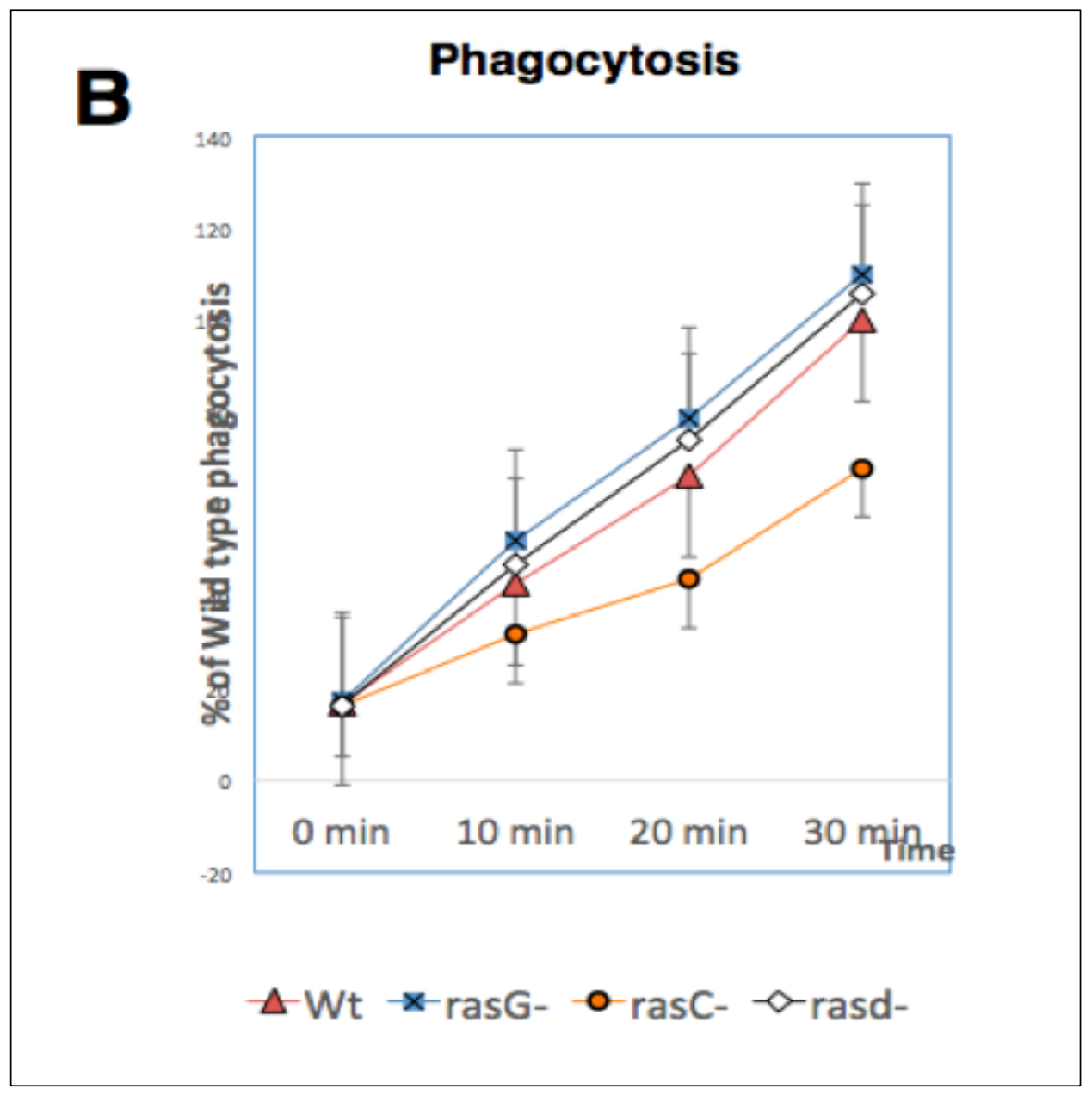




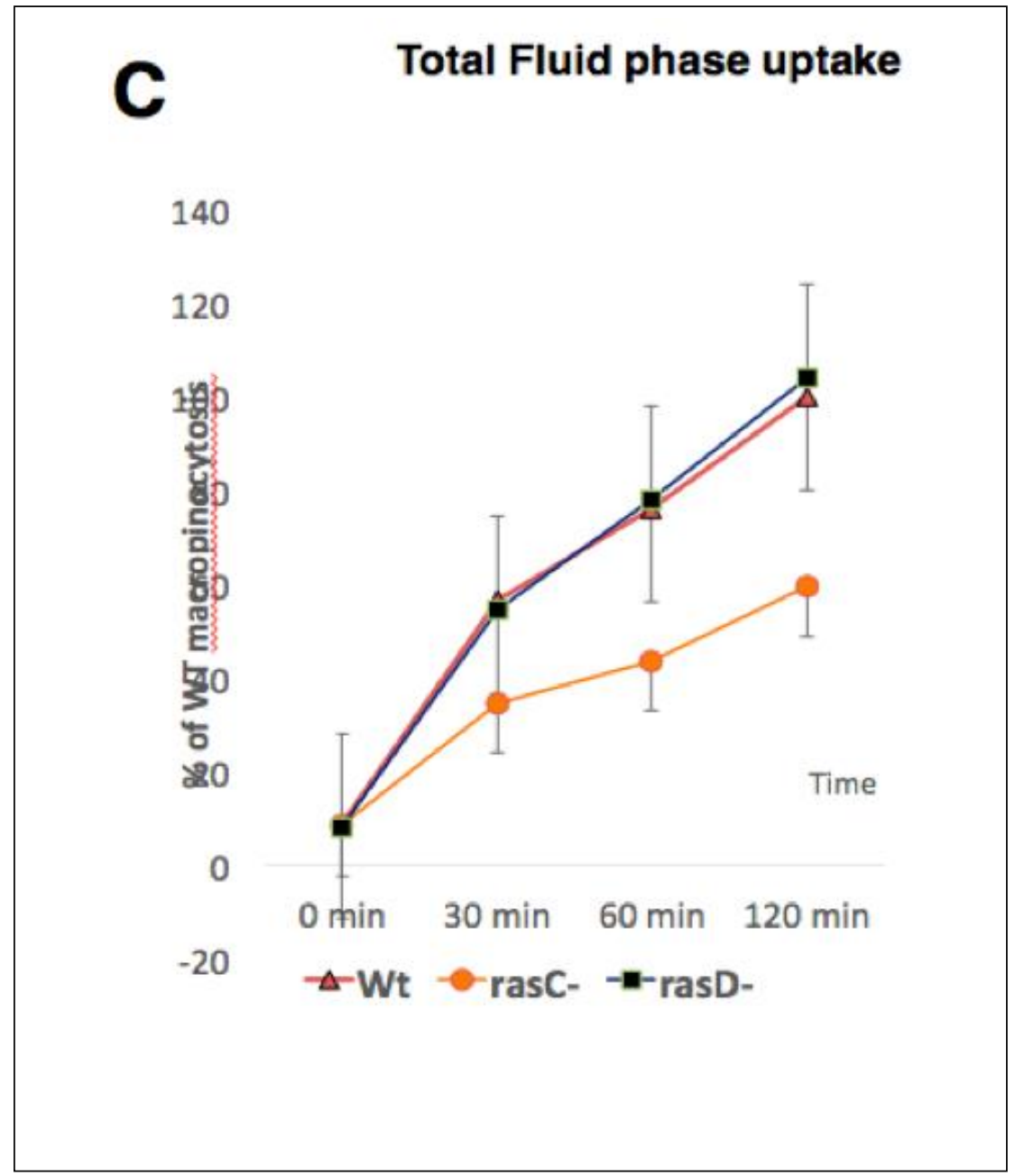

FIGURE 2 ROLE OF RAS GTPASES IN PARTICLE UPTAKE

A)Wild type cells transfected with GFP-RBD construct after treating with TRITC yeast show localization of active Ras on the phagosome b) wild type and different Ras mutant cells of Dictyostelium were treated with FITC dextran, lysed and the rate of micropinocytosis was measured using flour metric analysis. C) $\operatorname{ras} G-, \operatorname{ras} C$ - and $\operatorname{ras} D$ cells were mixed with TRITC yeast and spectrofluorometric analysis of number of yeast 
particles engulfed show ras $C$ - cells have a lower rate of phagocytosis, $r a s D$ - and ras $G$ cells engulfed at the same rate as wild type

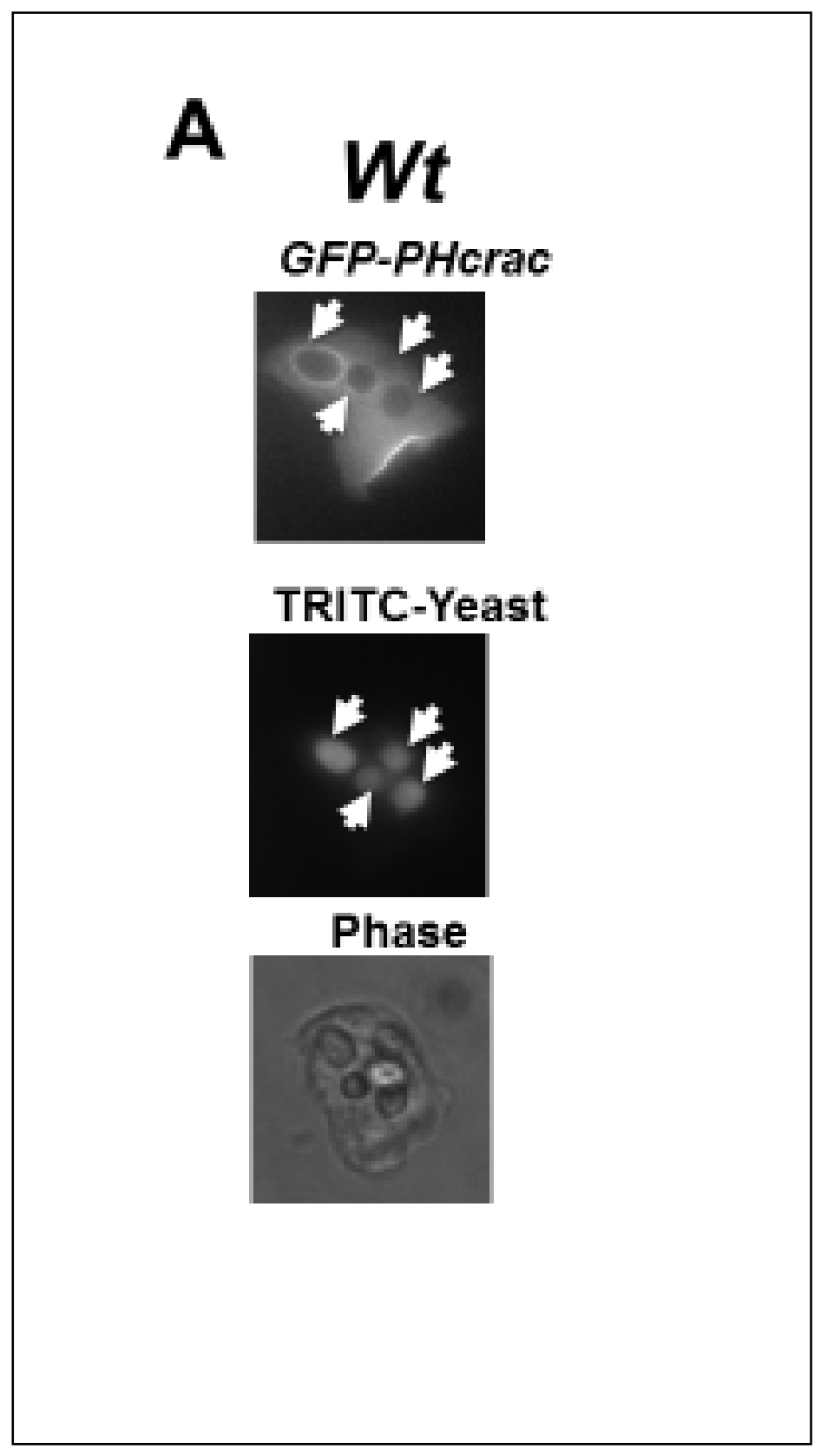




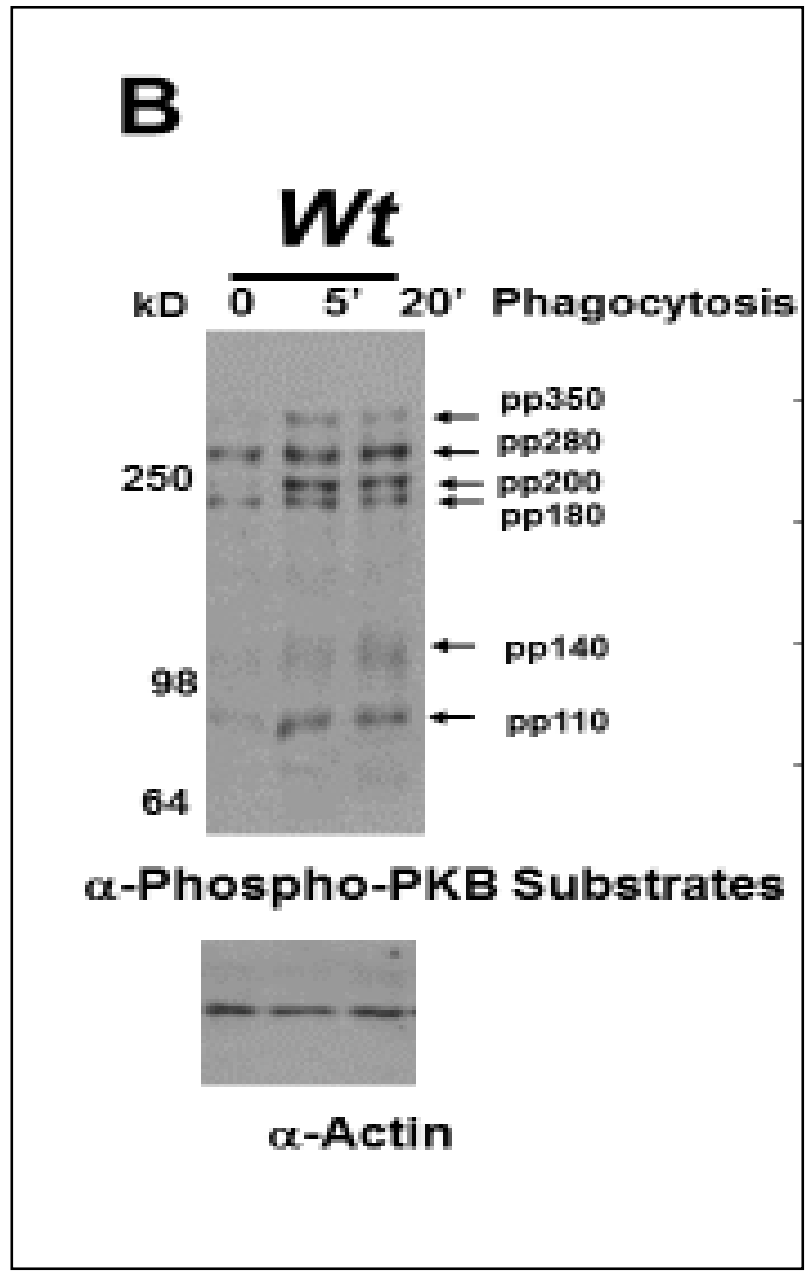

FIGURE 3 PIP3 IS INVOLVED IN PHAGOCYTOSIS AND PKB SUBSTRATES PHOSPHORYLATION

A) Wild type cells transfected with GFP- PHcrac mixed with TRICTC yeast cells showing the localization of PIP3 at the phagosome. B) Blot showing the phosphorylation of PKB substrate in wild type cells treated with yeast at different time intervals. 


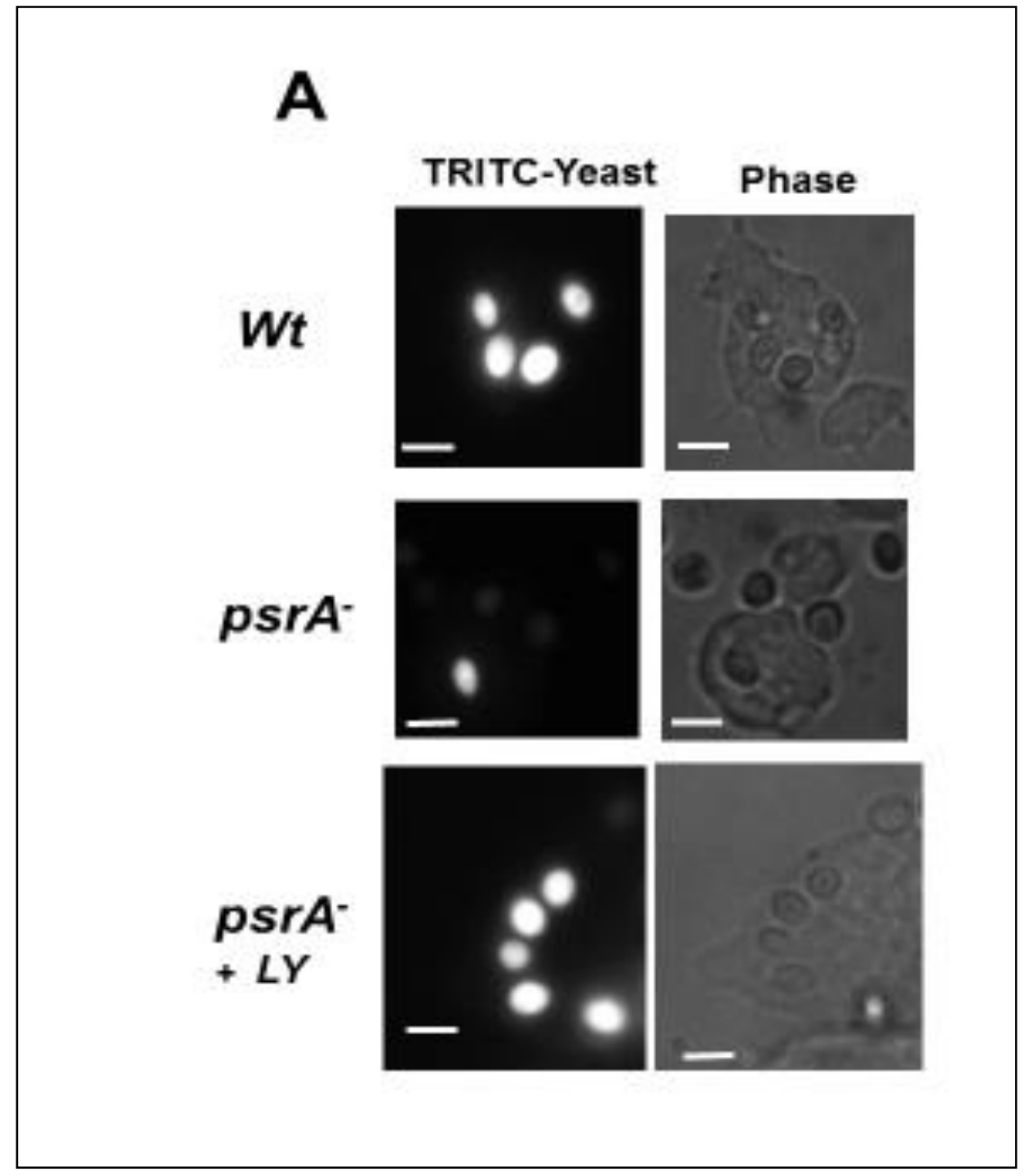




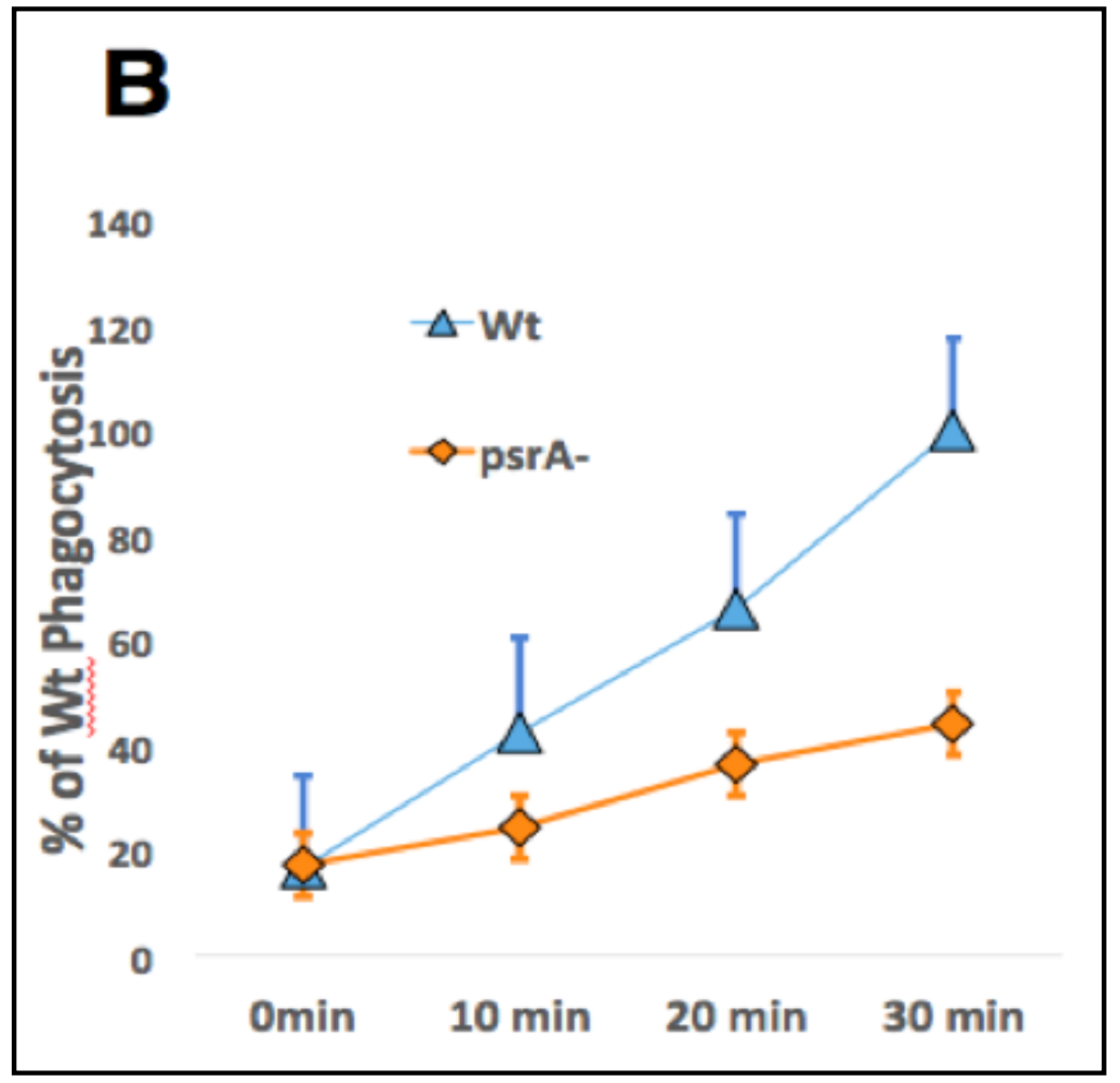




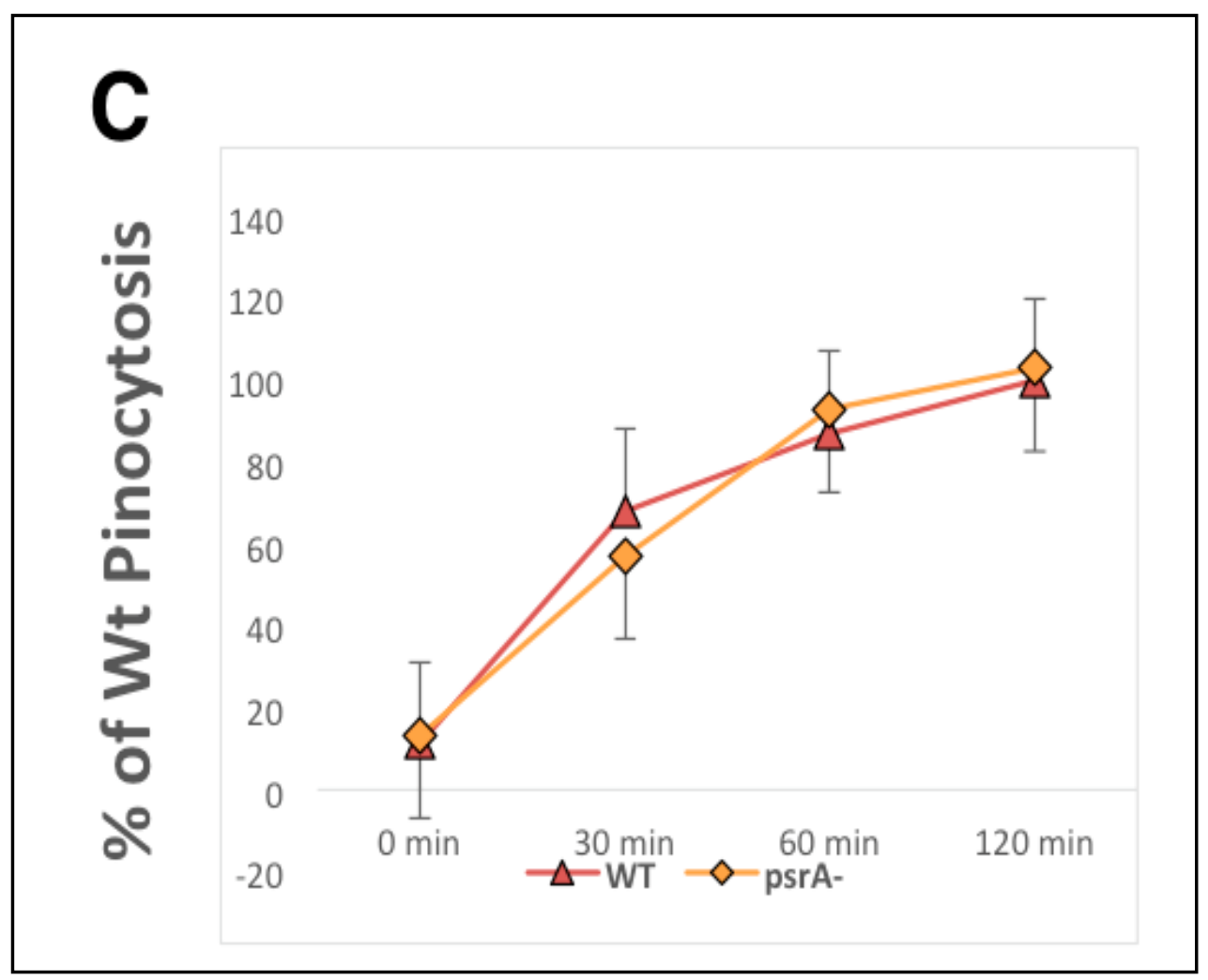

FIGURE 4 psrA- CELLS DISPLAY A DEFECT IN PHAGOCYTOSIS, BUT MACROPINOCYTOSIS IS NORMAL.

a) Wild type and $p s r A^{-}$mixed with TRITC labelled yeast under phase contrast and fluorescent microscope engulf lesser number of TRITC yeast. b) $p s r A^{-}$cells display a low rate of phagocytosis compared to wild type when mixed with TRITC yeast and quantified with a spectroflourimeter at excitation 515 and emission $474 \mathrm{C}$ ) spectrofluorometric analysis of macropinocytosis of FITC dextran by psrA compared to wild type cells 


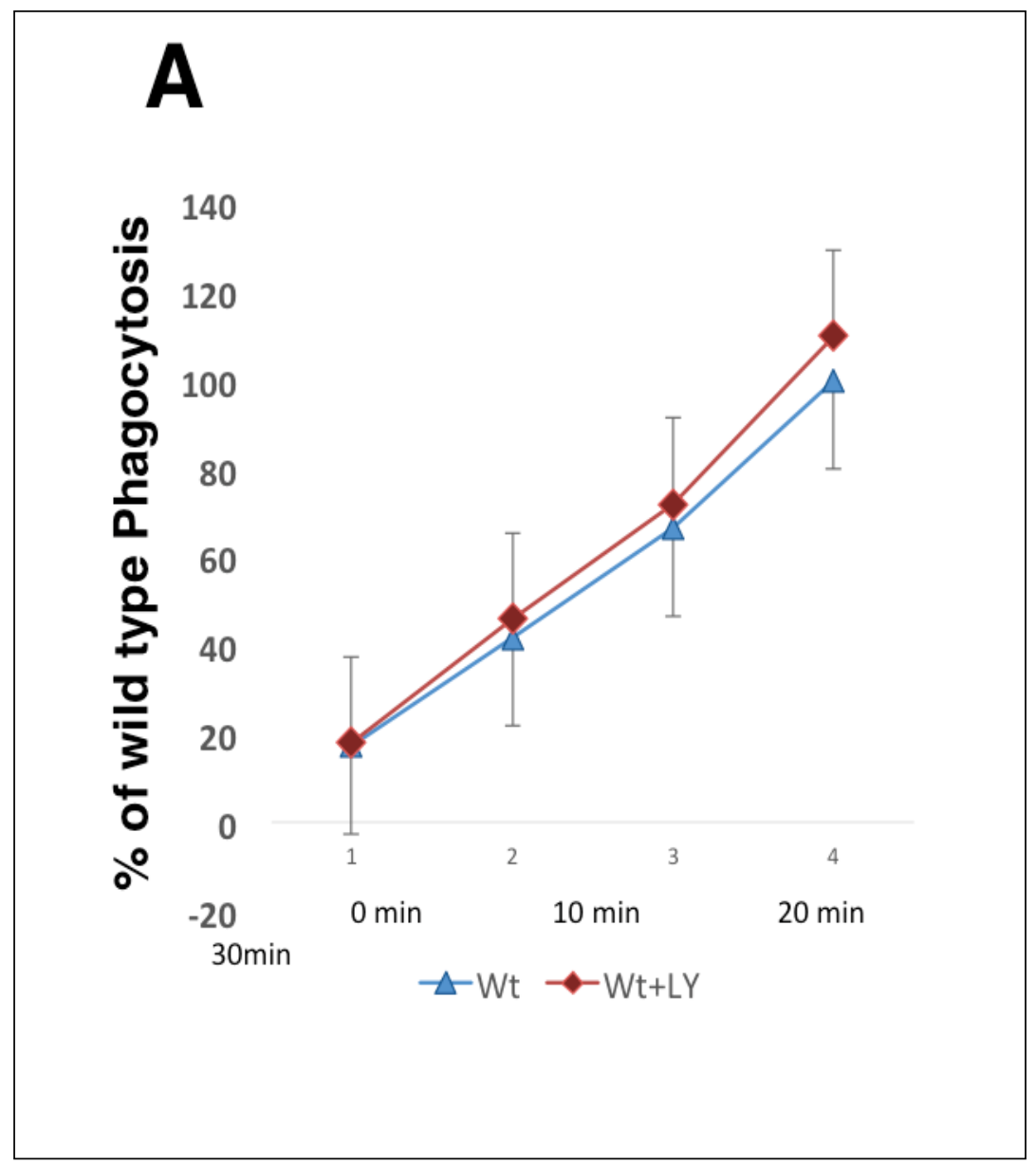




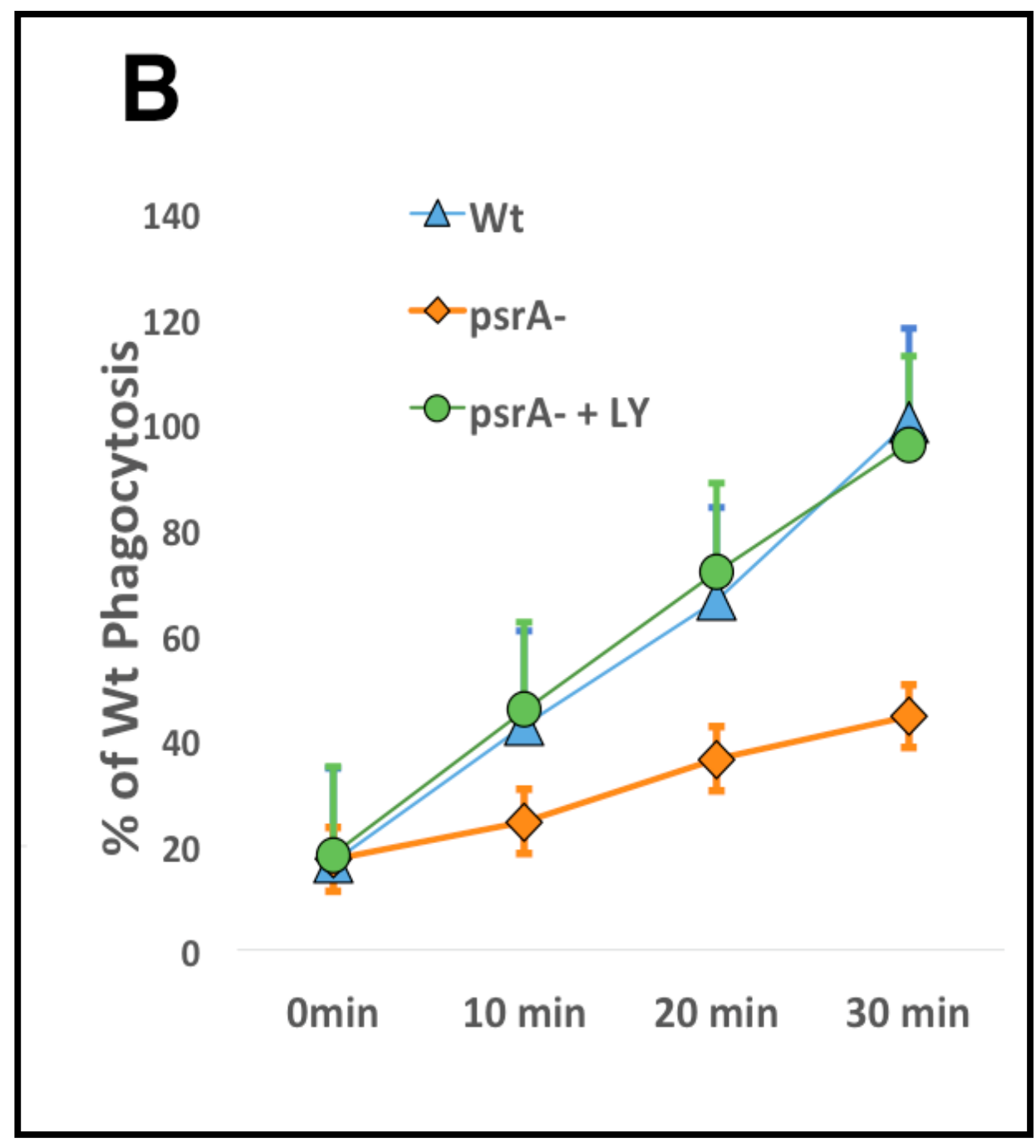

FIGURE 5 psrA- CELLS DISPLAY RESTORATION IN PHAGOCYTOSIS TO WILD TYPE LEVELS AFTER TREATMENT WITH 50 M LY 294002

A) Phagocytosis of wild type cells when treated with TRITC yeast in the presence and absence of 50 $\mu \mathrm{M}$ PI3K inhibitor LY249002 B) Phagocytosis of TRITC labelled yeast by psrA- cells in the presence and absence of $\mu$ M LY249002 


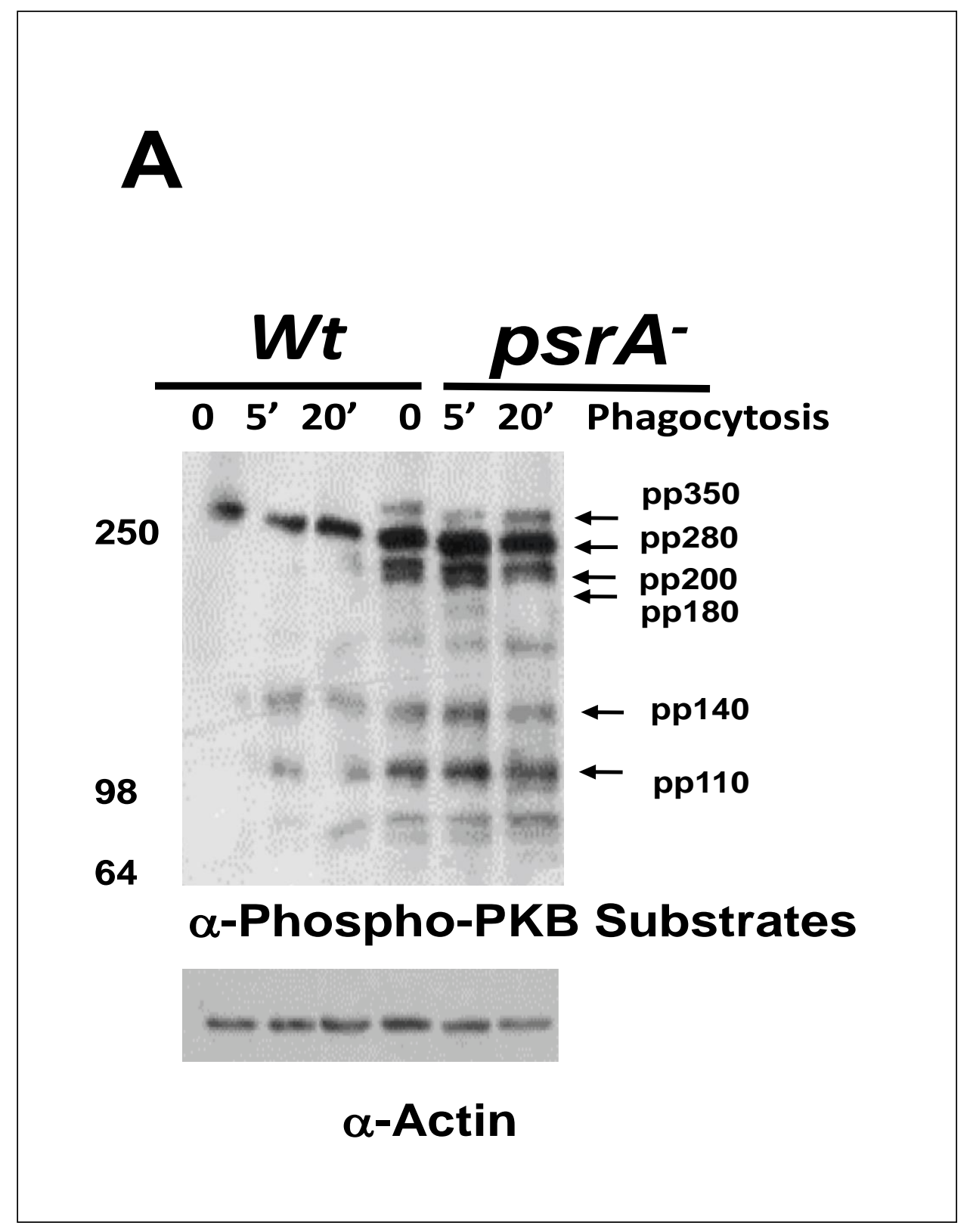




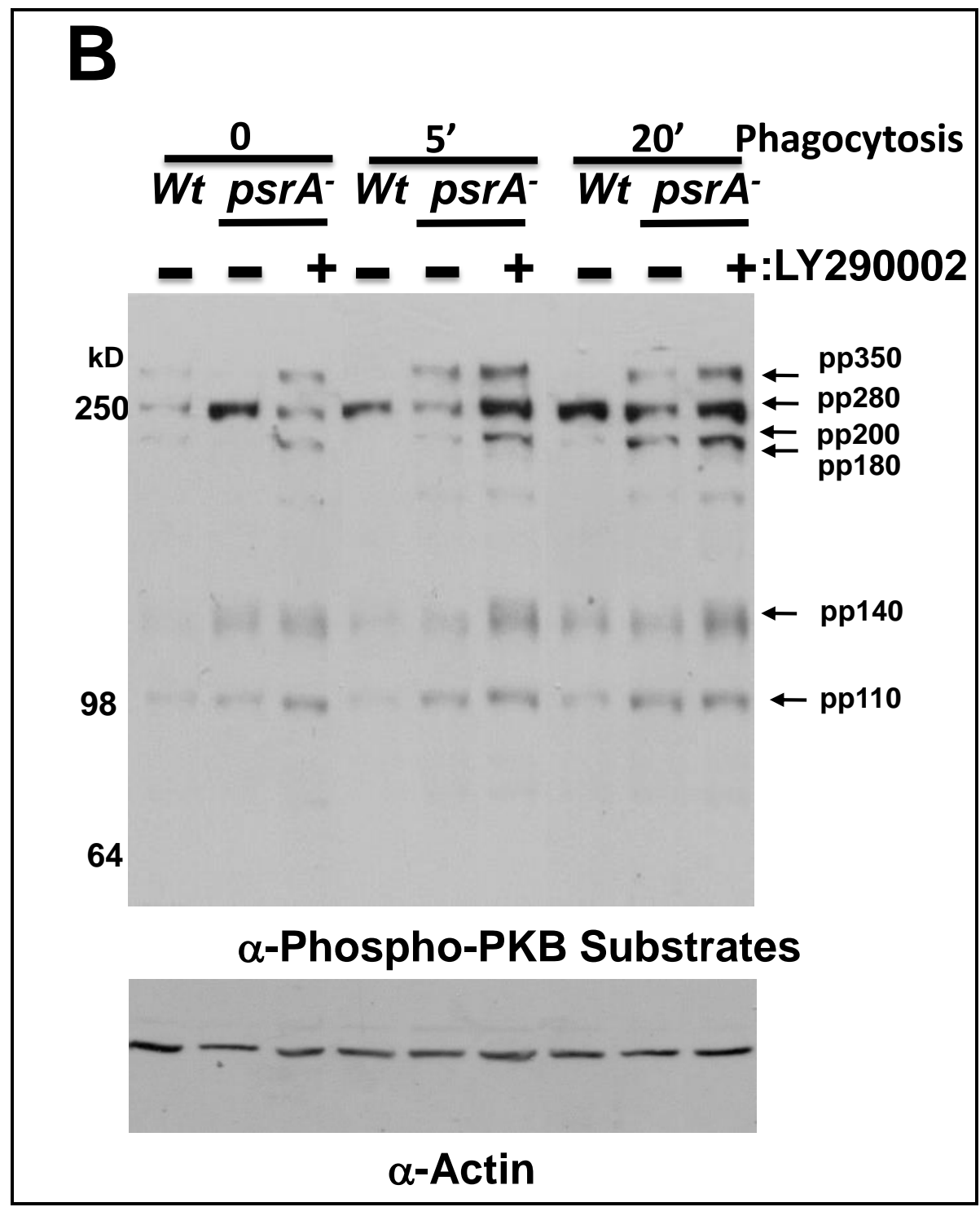

Figure 6 PSRA- CELLS SHOW ABERRANT PKB SUBSTRATE PHOSPHORYLATION

A) $\mathrm{PKB}$ substrate phosphorylation is higher in $p s r A^{-}$cells in comparison to the wild type cells B) The abberant PKB substrate phosphorylation is rescued to nearly wild type when psrA- cells was treated with LY 249002. 


\subsection{Discussion}

Transient accumulation of Phosphatidylinositol( $3,4,5) \mathrm{P} 3$ on a phagocytic cup was observed and reported in multiple studies utilizing Dictyostelium. Its role in phagocytosis, however, is still controversial due to the fact that smaller particle such as Latex beads and bacteria are relatively insensitive to PI3K inhibitor or cells lacking all five class I PI3K proteins (Buczynski et al., 1997, More ref). When cells phagocytosing larger particles such as yeast, reported evidence supports that certain PI3K activity or specialized PIP3 pool is involved in the efficient particle uptake (Cox et al., 1999, Dormann et al., 2004).

The five members of the class I Dictyostelium PI3K are targets of multiple Ras proteins. Two of the mostly extensively studied Ras proteins are RasG and asC. RasG is often assumed to be an upstream activator of PI3K and Akt family member PKBA, whereas $\mathrm{RasC}$ is an upstream activator of TorC2, which activate PKBR1, another Akt family member (Cai et al. 2010).

However, there also exist studies that do not fit to this commonly accepted model. udies (Lim, et al., 2001, 2005) demonstrated that RasC is also necessary to activate PKBA, which is supposed to be regulated by RasG. Interestingly, cells lacking Superoxide Dismutase $C(\operatorname{SodC})$ suffer high basal RasG activity with normal RasC activity, which supposed not to affect TorC2 and thus PKBR1, also displayed high level of PKBA and PKBR1 activity, suggesting that there is unidentified interaction between RasC and RasG (Kim lab, manuscript in preparation). 
One of the major differences between RasC and RasG is that unlike many other Ras proteins, such as RasG, RasS, RasD, RasB, and Rap1, RasC does not associate any of the five class I PI3K (Hoeller et al., ).

Recent studies uncovered that TorC2, one of the RasC downstream targets, suppresses phagocytosis of large particle (Rosel et al., 2012). The same study also demonstrated that cells lacking PKBA ( $\left.p k b A^{-}\right)$displayed significantly enhanced particle uptake, but upon expression of constitutive active version of TorC2 activator Rheb override the activation, strongly arguing that TorC2 can suppress particle uptake independent from Akt activity. It will be important to determine if $\mathrm{RasC}$ is involved under this situation, but it is yet to be tested experimentally.

The simplistic explanation of Akt mediated suppression of particle uptake would be that Akt inhibits Tsc, a RhebGAP, which will in turn activate TorC2 and thus inhibit phagocytosis. It is, however, not determined experimentally, and thus other possible mechanisms are not formally excluded yet. Considering that PI3K1 and PI3K2 are essential for macropinocytosis and ablation of their major downstream effector PKBA led to decreased fluid uptake, PKBA may passively discourage particle uptake by engaging cells to macropinocytosis. Consistently, $p k b A^{-}$cells displayed impaired fluid uptake activity (Rosel et al., 2012).

The current study confirmed that GFP-RBD protein, an active Ras sensor, transiently localized phagocytic cup, which disappear after internalization (Fig. 1A). Cells lacking RasC, but not RasG, exhibited significantly decreased TRITC-yeast uptake, indicating that $\mathrm{RasC}$ is a positive regulator of phagocytosis. $\mathrm{RasC}$ activates $\mathrm{TorC} 2 \mathrm{kinase}$ complex in the context of cAMP receptor mediated signaling cascade, it is puzzling that 
RasC, a positive activator of TorC2 complex (a negative regulator of phagocytosis), displayed decreased phagocytosis activity. We thus speculate that RasC may function as a positive regulator of phagocytosis independent from TorC2 regulation.

Studies concerning the role of $\mathrm{RasC}$ in fluid phase uptake uncovered contrasting results. One study discovered that $\mathrm{rasC}^{-}$cells performed enhanced fluid uptake and an overexpression of RasC into wild type cells suppressed the macropinocytic activity (Lim et al., 2005). Another study (Hoeller et al. 2013), however, reported that $\operatorname{ras} C^{-}$cells displayed wild type level activity of fluid phase uptake. We report here that $\operatorname{ras}^{-}$cells are compromised in the activity of macropinocytosis. Considering that RasC is necessary for PKB activation and cells lacking PKBA displayed significantly compromised macropinocytosis activity (Rosel et al., 2012), our observation that RasC is a positive regulator of macropinocytosis is consistent with the concept that PKB is a stimulating factor of macropinocytosis.

As mentioned before, when cells are phagocytosing larger particles such as yeast, certain PI3K activity or specialized PIP3 pool is involved in the efficient particle uptake (Cox et al., 1999, Dormann et al., 2004). We also corroborated that Dictyostelium cells expressing GFP-PHcrac, a PIP3 reporter, transiently exhibited PIP3 around the rim of phagocytic cup (Fig. 2A). To determine if the accumulated PIP3 signal is linked with PKB activation or other PIP3 dependent signaling events such as Adenylyl Cyclase activation through $\mathrm{PH}$ domain containing CRAC protein, $\mathrm{PKB}$ activity was indirectly monitored by observing phosphorylation of PKBs substrates (Fig. 2B). The phosphorylation of PKBs substrates were increased dramatically upon particle uptake of Dictyostelium cells. 
Cells before engaging in particle uptake activity display low basal level of phosphorylation on TalinB and p180 GefN, which we speculate that the self-activating Ras activity in cells exhibiting random motility may weakly activate PKB signaling and led to the limited basal PKBs substrate phosphorylation. The other possibility is that PKBs may function as another self-activating signaling component of cells in addition to the self-activating Ras, and thus induce low basal level of PKBs substrate phosphorylation.

After feeding with yeast, cells displayed significant increase in the phosphorylation of p350, p280 (TalinB), p200/p180 (GefN), p140 (GacQ/PakA), and p110 (GefS/PI5K).

When cells are aggregation competent, they activate PKBs in response to chemoattractant cAMP, which in turn leads to increased phosphorylation of above mentioned PKBs substrate phosphorylation which is critical for F-Actin remodeling involved in the cell migration. Considering that PKBA is regulating phagocytosis, it is thus important to determine if PKBs substrate phosphorylation is also accompanied with particle uptake process in addition to chemotaxis. The result shown here demonstrated that phagocytosis is accompanied with PKBs substrate phosphorylation. It is not surprising given that the phagocytosis is an F-Actin remodeling driven dynamic process. The pattern of phosphorylation of these PKBs substrates during phagocytosis were not identical with those during chemotaxis. TalinB was significantly phosphorylated under the context of both chemotaxis and phagocytosis, but p200/p180 GefN is more highly phosphorylated during phagocytosis and PakA showed the opposite (Fig. 2B). Although the lamellipodia at the leading edge and the phagocytic cup structures include dendritic 
Arp2/3 nucleated F-Actin, the gross structures are quite distinct and thus our observation of the distinct phosphorylation pattern of PKBs substrates during these two processes may play a role for generating the difference. The effects of PP2A/B56 and LKB1 on the phosphorylation of PKBs substrate during phagocytosis will be discussed later.

Considering that, as mentioned earlier, cells lacking PP2A/B56 displayed major defects in cell migration accompanied with aberrantly high levels of PKBs activity and that PKB activity suppresses particle uptake, we reasoned that PP2A/B56 may also modulate phagocytosis. $\mathrm{psrA}^{-}$cells indeed displayed significantly decreased phagocytosis of TRITC-yeast as expected (Fig. 3A and 3B). psrA cells displayed high level of PKBs activity, but no aberrantly high levels of $\mathrm{PI}(3,4,5) \mathrm{P} 3$ or active Ras were observed (Pino et al., 2015). As Hoeller and others (2014?) demonstrated RasG and RasS are upstream activators of PI3K1, PI3K2, and PI3K4, of which activation are critical for generating $\mathrm{PI}(3,4,5) \mathrm{P} 3$ containing membrane ruffles and their closing that conclude macropinocytosis. The same study, interestingly, showed that $\mathrm{Ras} C$ does not bind with any five of the class I Dictyostelium PI3K. Binding studies of GST-B56 with several Ras proteins uncovered that the Dictyostelium B56 subunit preferentially associate with RasC, but not with RasG. Consistent with these studies, no major aberrancy in macropinocytosis activity was observed from $p s r A^{-}$cells (Fig. 3C).

To further understand the mechanism of B56 mediated modulation of phagocytosis, a pharmacological inhibitor LY294002 was applied to wild type and $p s r A^{-}$ cells. As mentioned earlier, LY294002 inhibits pinocytosis through PI3K at concentrations around $15 \mu \mathrm{M}$, but could partially inhibit TorC2 activation with cAMP under higher concentration such as $\sim 50 \mu \mathrm{M}$ (Charest et al., 2012). Thus we reasoned that 
cells under significant TorC2 inhibition would in general exhibit higher particle uptake activity or certain cells, which harbor mutation in the TorC2 regulatory network, will be more sensitive toward TorC2 inhibition in terms of phagocytosis compared to wild type cells. Wild type cells treated with $50 \square$ M LY294002 exhibited no different phagocytic activity compared to that of untreated wild type cells, suggesting that there is only a low basal TorC2 activity during phagocytosis unlike chemotaxis, under which chemoattractant continues to activate TorC2 kinase activity. Rosel and other (2012) showed that the intact TorC2 complex is necessary to suppress phagocytosis, but it was not determined if RasC dependent activation of TorC2 is necessary for the suppression (. $p s r A^{-}$cells, in contrast to wild type cells, displayed constitutively high level of PKBs activity, which presumably requires constitutively higher level of TorC2 and PDK1/2 activities. This, in turn, will lead to higher phagocytosis that will be sensitive to LY294002. Figure 4B confirmed that this was the case.

The process of particle uptake accompanies increased phosphorylation of PKBs substrates as described earlier (Fig. 2B). Aggregation competent $p s r A^{-}$cells starved and stimulated with pulsatile cAMP for four hours displayed constitutively higher level of PKBs substrate phosphorylation (Pino et al., 2015). The current study uncovered that the growth phase (vegetative stage) $p s r A^{-}$cells also suffer from uncontrolled high basal phosphorylation of PKBs substrates, and TalinB, RasGefN, and RasGefS/PI5K phosphorylation persisted during the process of particle uptake (Fig. 5A). Considering that $p s r A^{-}$cells display high basal PKBs activity in the absence of high basal level of active Ras, PP2A/B56, together with PKBs activating upstream component TorC2 and PDK1/2, may constitute a self-activating signaling unit. In addition, we favor the view 
that the dysregulation of PKBs in $p s r A^{-}$cells likely occurs somewhere after Ras and before PKBs, given that LY294002 function at the downstream of active Ras. TorC2 and/or PDK1/2 are the mostly likely target of PP2A/B56.

In response to LY294002 treatment, psrA cells displayed attenuated phosphorylation levels of PKBs substrates similar to those of wild type cells. Most notably, the basal Talin B phosphorylation decreased dramatically, and the basal phosphorylation of p200/p180 GefN increased modestly. The basal phosphorylation level of p140 PakA and p110 GefS/PI5K did not change significantly. During the phagocytosis, $p s r A^{-}$cells displayed gradually increased phosphorylation of p350, p280 Talin B, p200 GefN that were largely comparable to those of wild type cells. Considering that TalinB is the one that mediates the adhesion between a particle and the cell, and that GefN could activate Ras proteins, although its identity is yet to be determined, it is highly likely that PKBs-mediated phosphorylation of TalinB and GefN are likely the central events during the phagocytosis.

\subsection{References}

Bosgraaf, L., \& van Haastert, P. J. M. (2006). The regulation of myosin II in Dictyostelium. European Journal of Cell Biology, 85(9-10), 969-979. http://doi.org/10.1016/j.ejcb.2006.04.004

Bretschneider, T., Anderson, K., Ecke, M., Muller-Taubenberger, A., SchrothDiez, B., Ishikawa-Ankerhold, H. C., \& Gerisch, G. (2009). The three-dimensional dynamics of actin waves, a model of cytoskeletal self-organization. Biophysical Journal, 96(7), 2888-2900.

Cai, H., Das, S., Kamimura, Y., Long, Y., Parent, C. A., \& Devreotes, P. N. (2010). Ras-mediated activation of the TORC2-PKB pathway is critical for chemotaxis. Journal of Cell Biology, 190(2), 233-245. 
Cornillon, S., Froquet, R., \& Cosson, P. (2008). Involvement of sib proteins in the regulation of cellular adhesion in Dictyostelium discoideum. Eukaryotic Cell, 7(9), 16001605.

Dormann, D., Weijer, G., Dowler, S., \& Weijer, K. (2004). In vivo analysis of 3phosphoinositide dynamics during Dictyostelium phagocytosis and chemotaxis. Journal of Cell Science, 117(Pt 26), 6497-6509.

Gerisch, G., Schroth-Diez, B., Müller-Taubenberger, A., \& Ecke, M. (2012). PIP3 waves and PTEN dynamics in the emergence of cell polarity. Biophysical Journal, 103(6), 1170-1178

Haas, A. (2007). The phagosome: Compartment with a license to kill. Traffic, 8(4), 311-330.

Hoeller, O., Bolourani, P., Clark, J., Stephens, L. R., Hawkins, P. T., Weiner, Kay, R. R. (2013). Two distinct functions for PI3-kinases in macropinocytosis. Journal of Cell Science, 126, 4296-307

Maniak, M., Rauchenberger, R., Albrecht, R., Murphy, J., \& Gerisch, G. (1995). Coronin involved in phagocytosis: Dynamics of particle-induced relocalization visualized by a green fluorescent protein tag. Cell, 83(6), 915-924.

Peracino, B., Balest, A., \& Bozzaro, S. (2010). Phosphoinositides differentially regulate bacterial uptake and Nramp1-induced resistance to Legionella infection in Dictyostelium. Journal of Cell Science, 123(Pt 23), 4039-4051.

. Pino, M. R., Castillo, B., Kim, B., \& Kim, L. W. (2015). PP2A/B56 and GSK3/Ras suppress PKBs activity during Dictyostelium chemotaxis. Molecular Biology of the Cell, 26(24), 4347-4357.

Peracino, B., Borleis, J., Jin, T., Westphal, M., Schwartz, J. M., Wu, Bozzaro, S. (1998). G protein $\beta$ subunit-null mutants are impaired in phagocytosis and chemotaxis due to inappropriate regulation of the actin cytoskeleton. Journal of Cell Biology, 141(7), 1529-1537.

Rosel, D., Khurana, T., Majithia, A., Huang, X., Bhandari, R., \& Kimmel, A. R. (2012). TOR complex 2 (TORC2) in Dictyostelium suppresses phagocytic nutrient capture independently of TORC1-mediated nutrient sensing. Journal of Cell Science, 125(Pt 1), 37-48.

Tang, M., Iijima, M., Kamimura, Y., Chen, L., Long, Y., \& Devreotes, P. (2011). Disruption of PKB signaling restores polarity to cells lacking tumor suppressor PTEN. Molecular Biology of the Cell, 22, 437-447. 
Vogel, G., Thilo, L., Schwarz, H., \& Steinhart, R. (1980). Mechanism of phagocytosis in Dictyostelium discoideum: Phagocytosis is mediated by different recognition sites as disclosed by mutants with altered phagocytotic properties. Journal of Cell Biology, 86(2), 456-465 


\section{CHAPTER 3: LKB1 INHIBITS PHAGOCYTOSIS AND CELL ADHESION}

\subsection{Summary}

In this chapter, we described the role of Dictyostelium LKB1 in the process of particle uptake. As previously reported by Veeranki and others (2011), we also opted the $R N A i$ based knockdown strategy to investigate the role of LKB1 in phagocytosis. $L K B 1$ $R N A i$ cells $\mathrm{n}$ displayed a two-fold increase in phagocytosis and significantly increased level of adhesion to substratum, but normal rate of fluid uptake activity. At the molecular level, LKB1-RNAi cells showed significantly higher level of PKBs substrates phosphorylation. The pattern of PKBs substrate phosphorylation in $L K B 1-R N A i$ cells was not identical with that in $p s r A^{-}$cells, and treatment of LY294002 did not change the higher level of particle uptake activity of $L K B 1-R N A i$ cells.

\subsection{Introduction}

LKB1 is a well-known tumor suppressor of which inactivation often lead to a Peutz-Jeghers syndrome, which is accompanied with intestinal polyps with significantly increased risk of intestinal cancer (Mehenni et al. 1998). In lower eukaryotes, LKB1 contributes PAR system mediated polarization process of C. elegans (Chartier et al. 2011), epithelial polarity regulation in Drosophila (Martin \& St Johnstone 2003), and regulates cell differentiation through activating GSK3 in Dictyostelium (Veeranki et al., 2011). LKB1 plays a critical role in stress response by activating AMP Kinase (AMPK) in both Dictyostelium and mammalian cells (Woods et al. 2003). Among over dozen targets of AMPK, a small GTPase Rheb regulatory 


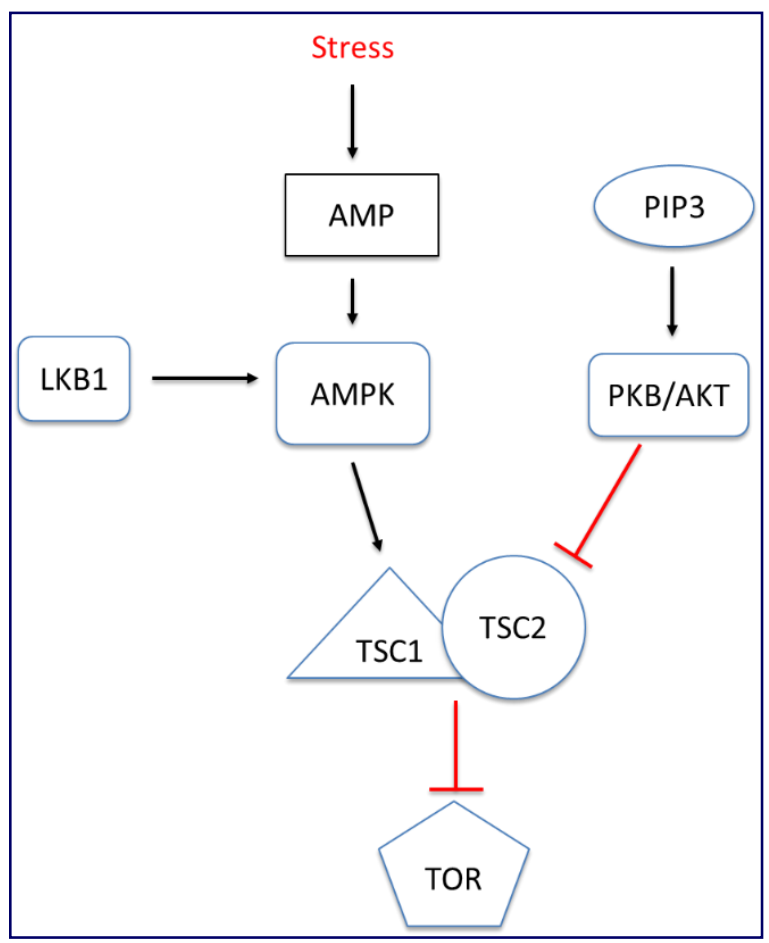

\section{FIGURE 7 REGULATION OF LKB1 IN MAMMALIAN SYSTEM}

Regulation of TOR by LKB1 through TSC1/TSC2 pathway in the mammalian system under stress condition. PIP3 has an inhibitory effect on TSC1/TSC2

protein Tsc1/2 is a known AMPK target (Lacher et al. 2011), which could potentially affect phagocytosis. The Tsc1/2 and Rheb signaling axis in mammalian system activates TorC1, but not TorC2. A recent study, however, demonstrated that Tsc $2 /$ Rheb signaling pathway not only exist, but activate TorC2 in Dictyostelium (Rosel et al., 2012). The presence of the intact TorC2 protein complex, which is comprised of four components Rictor (Pia), Sin1 (Rip3), Lst8, and the kinase subunit TOR, was essential for TorC2 mediated suppression of particle uptake of Dictyostelium cells (Rosel, et al., 2012). 
Interestingly, the TorC2 mediated inhibition of Phagocytosis is independent of PKBs. The result described in this chapter is one of the few reports that LKB1 can modulate FActin driven cellular processes such as phagocytosis. Xu and other (2010) reported that LKB1 regulates thus F-Actin remodeling.

\subsection{Materials and methods}

\subsubsection{Cell culture}

The different strains will be grown in D3T media (15.30 g Peptone \#3, $7.15 \mathrm{~g}$ of Yeast extract, 15.4 g Glucose, $0.48 \mathrm{~g} \mathrm{KH}_{2} \mathrm{PO}_{4}, 0.525 \mathrm{~g} \mathrm{Na}_{2} \mathrm{PO}_{4} .7 \mathrm{H}_{2} \mathrm{O}, \mathrm{H}_{2} \mathrm{O}$ to complete 1L). All strains were supplemented with $0.5 \mathrm{mg} / \mathrm{ml}$ thymidine (since all my cells and mutants were derived from the JH1O wild type strain). Additionally, $5 \mathrm{ng} / \mu \mathrm{l}$ blasticidin were added to all transformants in the $S o d C^{-}$background, and G418 $20 \mu \mathrm{g} / \mu 1$ to all Ras overexpressors.

Cells were kept in Nunc stationary culture flasks (Thermo scientific cat\# 136196) at 20 degrees Celsius. For most experimental purposes cells were grown in shaken suspension at $150 \mathrm{rpm}$ (Wats and Ashworth, 1970) to a density of $\sim 2.5 \times 10^{6}$ cells $/ \mathrm{mL}$. The cells number will be obtained using a hemocytometer. After this, cells will be harvested and used for the different experiments.

\subsubsection{Western blot}

Dictyostelium cells were harvested by centrifugation and were lysed with complete TTG ( $1 \%$ Triton, 5\% Glycerol, $0.15 \mathrm{M} \mathrm{NaCl}, 20 \mathrm{mM}$ TRIS HCl pH 7.7, $1 \mathrm{mM}$ EDTA, 1mM sodium orthovanadate, $40 \mathrm{mM}$ ammonium molybdate, $1 \%$ BME, 1 table of protease inbitor/10 $\mathrm{ml}$ of TTG). $1 \mathrm{ml}$ of complete TTG was used to lyse 25 million cells. Protein 
lysates were mixed with $4 \mathrm{x}$ LDS sample loading buffer and boiled at $100^{\circ} \mathrm{C}$ for 3 minutes.

The cell lysates were fractionated by SDS-PAGE gel electrophoresis (Sambrook et al., 1989). The fractionated proteins were transferred on a nitrocellulose membrane and blocked with $2 \%$ Bovine serum albumin for 25 minutes. A suitable primary antibody was added, incubated overnight and a enzyme linked secondary antibody specific to the primary antibody was added and incubated for 3 hours. The bound secondary antibody was detected by chemiluminescence and thus normalized accordingly.

SDS-polyacrylamide gel electrophoresis was utilized to fractionate and normalize the proteins lysates. Proteins were transferred onto nitrocellulose membranes (Millipore) once the electrophoresis was done, blocked with a 2\% BSA (Amresco) for $30 \mathrm{~min}$ and probed overnight at 4 degrees $\mathrm{C}$ or 2 hours at room temperature using a suitable antibody. The bound antibody was detected by means of enhanced chemiluminescence (ECL, Cell Signaling Technology).

\subsubsection{Analysis of Phagocytosis using TRITC labelled yeast}

Cells in the log phase were pelleted in a table top centrifuge and re-suspended in media at a concentration of $2 \times 10^{6}$ cells/ml. TRITC beads were added at a concentration six fold to that of Dictyostelium cells. At different time intervals, $1 \mathrm{~mL}$ of the sample was withdrawn, added to $100 \mu \mathrm{L}$ of tryphan blue and incubated for $3 \mathrm{~min}$. The samples will be then centrifuged, re-suspended in Sorensen phosphate buffer $\left(2 \mathrm{mM} \mathrm{Na} \mathrm{HPO}_{4}, 15 \mathrm{~m} M\right.$ $\mathrm{KH} 2 \mathrm{PO} 4, \mathrm{pH} 6.0$ ) and the fluorescence was read in fluorimeter ( Excitation $544 \mathrm{~nm}$; emission $574 \mathrm{~nm}$ ). For the PKB substrate phosphorylation, the cells were treated with 
yeast at different time points and lysed with $1 \mathrm{x}$ complete TTG at the concentration of 1 $\mathrm{ml}$ per 25 million cells and the lysates were fractionated using SDS-PAGE and western blot was performed as described earlier. The nitrocellulose membrane from the western blot was treated with Phospho-Akt Substrate (RXXS*/T*) (110B7E) (cell signaling technologies).

\subsubsection{Pinocytosis Assay}

Cells in the log phase were pelleted in a table top centrifuge and re-suspended in media at a concentration $5 \times 10^{6}$ cells $/ \mathrm{ml}$. FITC dextran will be added at a concentration of $100 \mu \mathrm{L}$ for $5 \mathrm{~mL}$ of the cells suspended in media. $0.5 \mathrm{~mL}$ of the sample was drawn and added to $1.5 \mathrm{~mL}$ of ice cold Sorensen buffer ( $2 \mathrm{mM} \mathrm{Na}_{2} \mathrm{HPO}_{4}, 15 \mathrm{mM} \mathrm{KH} \mathrm{PO}_{4}, \mathrm{pH} 6.0$ ) and centrifuged. Further was washed once with Sorensen buffer, centrifuged and $1 \mathrm{ml}$ of lysis buffer ( $50 \mathrm{mM} \mathrm{Na}_{2} \mathrm{HPO}_{4}, \mathrm{pH} 9.4,0.2 \%$ triton $\left.\mathrm{X}-100\right)$ and the fluorescence will be measured using a fluorimeter (Excitation $470 \mathrm{~nm}$, Emission $515 \mathrm{~nm}$ ).

\subsubsection{Bacterial cell culture}

The E. coli bacterial cells were grown overnight in $100 \mathrm{ml}$ LB medium plus 50ug/mL ampicillin for about 16 hours at 37 degrees $C$ and $200 \mathrm{rpm}$. A stock of the cells containing the different plasmids was made in final $30 \%$ glycerol solution and stored at 80 degrees $\mathrm{C}$ for future use. After that, cells were pelleted using a IEC CL30R centrifuge at $4000 \mathrm{rpm}$ for 25 minutes. The DNA was obtained from the pellet using the Midi-Prep kit from Quiagen. After measuring optical density at $260 \mathrm{~nm}$ using the GENESYS 10uv spectrophotometer, the pellets were stored at -20 degrees $\mathrm{C}$ for future use. 


\subsubsection{Transfection}

Five million of Dictyostelium exponentially growing cells were centrifuged for 5 min at $2000 \mathrm{rpm}\left(4^{\circ} \mathrm{C}\right)$, washed once with $\mathrm{H}-50$ and resuspended in $100 \mu \mathrm{l}$ of $\mathrm{H}-50$. The cells were mixed with $10 \mu \mathrm{g}$ of desired DNA, and placed in a cold $0.1 \mathrm{~cm}$ Fisher electroporation cuvette (cat\# FB101). Electroporation will be done at $1 \mathrm{kV}$ two times with a pause of $5 \mathrm{sec}$ between pulses. Cells were placed in a ice for 5 minutes and then transferred into a $10 \mathrm{~cm}$ Petri dish with $10 \mathrm{ml}$ of D-3T media, supplemented with 0.5 $\mathrm{mg} / \mathrm{mL}$ thymidine. After $24 \mathrm{~h}, \mathrm{G} 418$ was added as a means of selection. This method was modified from Schauer et al., 1993.

\subsubsection{Cell adhesion assay}

Adhesion of cells to a solid matrix was performed as described (Khurana et al., 2005). Log-phase cells were plated on tissue culture dishes and allowed to settle for 2 hours. The dishes were then shaken for 60 minutes at varying speeds. Unattached cells were removed and counted using a hemocytometer.

\subsection{Results}

\subsubsection{LKB1 inhibits phagocytosis but no effect on fluid uptake.}

A previous study uncovered that several cellular stresses activate LKB1 kinase activity in Dictyostelium (Veeranki et al., 2011). In response to hyperosmotic stress, cells cringe and decrease their volume up to $\sim 50 \%$ by forming contractile cortical F-Actin bundles. Considering that LKB1 activation is accompanying this hyperosmotic response of F-Actin remodeling, and that mammalian AMPK, the most prominent LKB1 target, is linking osmotic stress to cortical F-Actin remodeling in response to osmotic stress signal 
(Miranda et al., 2010), it is highly likely that LKB1 play a critical role in cortical F-Actin remodeling. It is, however, not clear how LKB1 and/or AMPK are affecting cortical FActin remodeling and if other pathways that activate LKB1 could also affect cortical FActin remodeling.

One of the cellular events that involve cortical F-Actin remodeling is phagocytosis and thus cells lacking LKB1 activity may suffer aberrant particle uptake activity. LKB1 is a multifunctional regulatory kinase involved in a number of cellular events, and our previous effort to generate LKB1-null strain proved to be unsuccessful. Instead of LKB1-null strain, LKB1 knockdown strategy utilizing LKB1-RNAi strategy was successful (Veeranki et al., 2011). The LKBI-RNAi construct as reported previously (Veeranki et al., 2011) was used to generate $L K B 1-R N A i$ cells as described in methods and materials.

LKB1-RNAi cells in an exponential growth phase were fed with TRITC-yeast and internalized fluorescence value was measured after quenching the excess TRITC yeast with Tryphan Blue. The phagocytosis efficiency was quantitated by total measuring internalized FITC fluorescence value divided by the total mass of host cells used for each assay as described in the Materials and Methods. 200\% increase in fluorescence was observed from $L K B 1-R N A i$ cells compared to that of wild type (Fig. 6B). Fluorescent and phase contrast microscopic images taken at 30 min of phagocytosis also supported the observation that $L K B 1-R N A i$ cells are severely compromised in the particle uptake (Fig. 6A). To further confirm the inhibitory effects of LKB1 on phagocytosis, T7-LKB1 expression construct was introduced into wild type cells. The T7-LKB1 expressing cells 
were fed with TRITC-yeast and the efficiency of particle uptake was quantitated as described earlier. The T7-LKB1 expressing cells displayed $\sim 90 \%$ decrease in particle uptake by quantitative spectrofluorescence measurement, which was also supported by microscopic analysis as shown in figure $6 \mathrm{~A}$.

\subsubsection{PKB substrate phosphorylation is high in $L K B 1-R N A i$ cells and no restoration by LY treatment.}

Exhibition of dramatic enhancement of particle uptake of LKB1-RNAi cells invited an examination of PKB mediated cytoskeleton remodeling during phagocytosis. As shown previously, $p s r A^{-}$cells displayed aberrantly high basal levels of PKBs substrates phosphorylation and significantly compromised phagocytosis. To determine the PKBs substrate phosphorylation pattern in LKBI-RNAi cells during the course of particle uptake, LKB1-RNAi cells were fed with yeast and whole cell lysates were prepared at 0 , 5, and 20 minutes of yeast feeding. The lysates were normalized by anti-Actin western blot, and the normalized lysates were analyzed with anti-phospho-PKB substrates antibody (Fig. 7A). Surprisingly, $L K B 1-R N A i$ cells exhibited significantly higher level of PKBs substrate phosphorylation. All of the previously described targets of PKBs that include p350, p280 TalinB, p200/p180 RasGefN, p140 GacG/PakA, p110 gefS/PI5K, and p65 GacQ were highly phosphorylated in $L K B 1-R N A i$ cells before the onset of particel uptake. As the phagocytosis progresses, the intensities of phosphorylation of these PKBs substrates diminished modestly, but still significantly higher than those of wild type cells. The levels of phosphorylation of the two of the PKBs substrates, p200 RasGefN and p140 GacA/PakA, were much higher than the other members of PKBs substrates in LKB1-RNAi cells. These proteins may play a positive role in phagocytosis, but likely a 
target of LKB1 to control phagocytosis. It is clear that the mere increase of PKBs substrate phosphorylation is not a regulatory switch for phagocytosis. Hyperphosphorylation of RasGefN, GacQ, and PakA are likely to stimulate dendritic F-Actin remodeling accompanying phagocytosis. Consistent with this view, a previous study demonstrated that PakA localizes at the bottom of phagocytic cup and stimulates phagocytosis (Müller-Taubenberger et al., 2002).

Given that $L K B 1-R N A i$ cells display high levels of PKB activities, suppression of one of their upstream activator PI3K activity may alleviate its aberrantly high level of phagocytosis. To this end, wild type and LKB1-RNAi cells were treated with PI3K inhibitor LY294002 and their phagocytic activity was quantitated using TRITC-yeast as described before. Upon treatment with $50 \square$ M LY294002, higher level of PKBs substrate phosphorylation in LKB1-RNAi cells persisted unlike LY294002 treated psrA cells (Fig. 7A and Fig. 5B), indicating distinct mode of dysregulation. Figure 7B also shows that treatment of wild type cells with $50 \square \mathrm{M}$ of LY 294002 induced no inhibitory effect on phagocytosis in wild type cells. Under the same concentration of LY294002 treatment, LKB1-RNAi cells phagocytosed TRITC-yeast at still much higher rate (Fig. 7C).

\subsubsection{Cell-to-matrix adhesion and fluid uptake activity of LKB1-RNAi and $p s r A^{-}$ cells.}

One of the prerequisites for regular particle uptake is uncompromised cell adhesion activity. Obviously, without adhesion, there will be no particle uptake. To determine the cell adhesion efficiency of $p s r A^{-}$and $L K B 1-R N A i$ cells compared to that of wild type cells, an adhesion assay that measures cell to matrix adhesion was adopted as described in the materials and methods. Cells in growth media were plated on a plastic Petridis to 
secure adequate adhesion, and then shaken on a rotatory shaker at increasing speed of 50, 70, and $100 \mathrm{rpm}$ for one hour (Rosel et al., 2011) and cells detached from the surface of the Petridish were counted as shown in figure 8A. LKB1-RNAi cells displayed two-times lower number of cell detachment, whereas $p s r A^{-}$cells exhibited similar level of detachment as that of wild type cells. Considering that although higher phosphorylation of TalinB was commonly observed from both $L K B 1-R N A i$ and $p s r A^{-}$cells but distinct adhesion and phagocytic efficiencies were displayed, it is likely that other phospho-PKBs substrates can differentially regulate adhesion and phagocytic events through PKB1 and PP2A/B56. Lastly, total fluid uptake activity of $L K B 1-R N A i$ and $p s r A^{-}$cells were determined as described earlier. Cells were fed with fluid phase marker TRITC-dextran and the internalized fluorescence was quantitated. Unlike $\operatorname{ras}^{-}$cells reported earlier, no significant difference in fluid uptake activity was monitored from neither $L K B 1-R N A i$ nor psrA cells (Fig. 8B) 


\subsection{Figures}

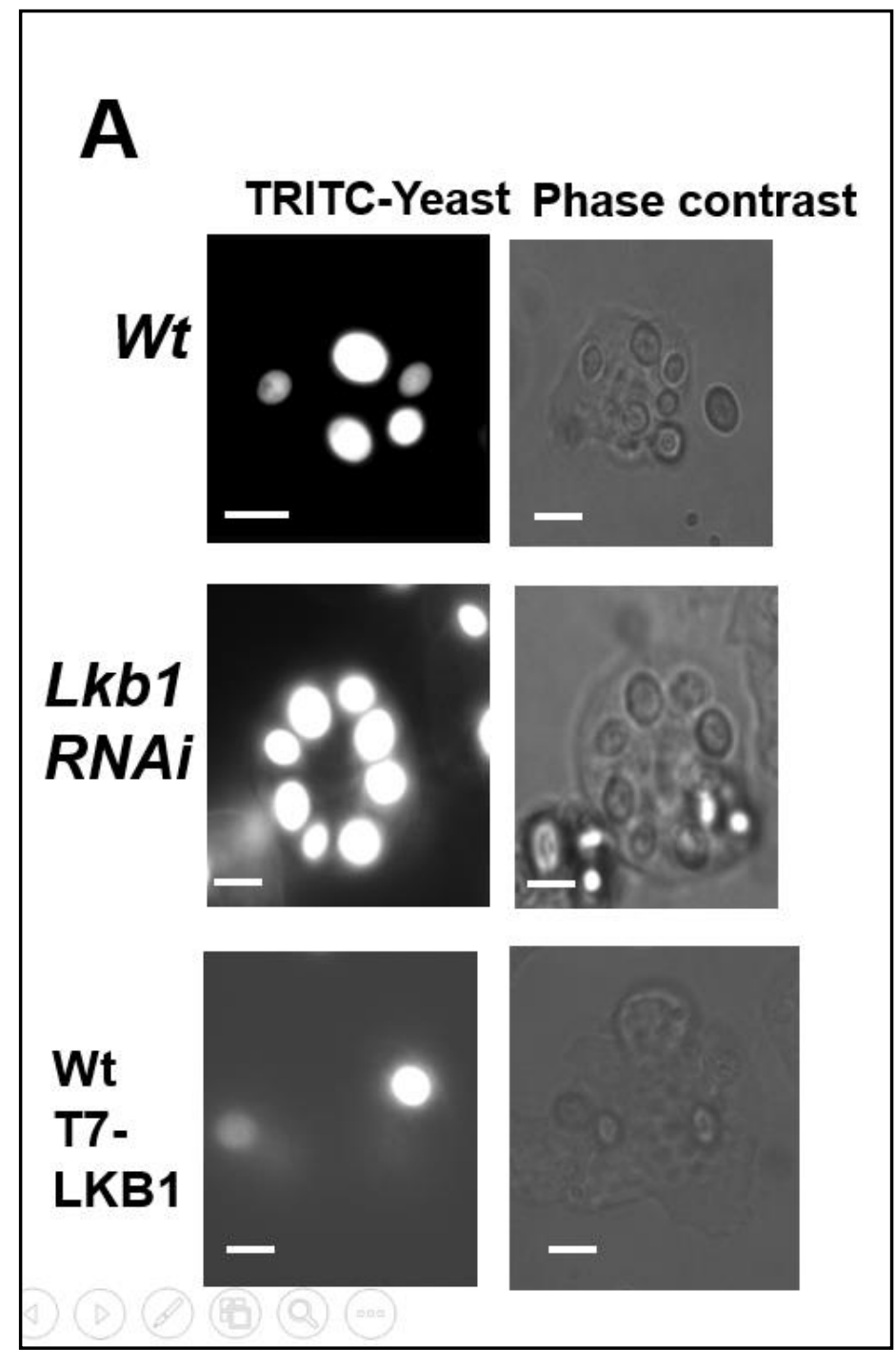




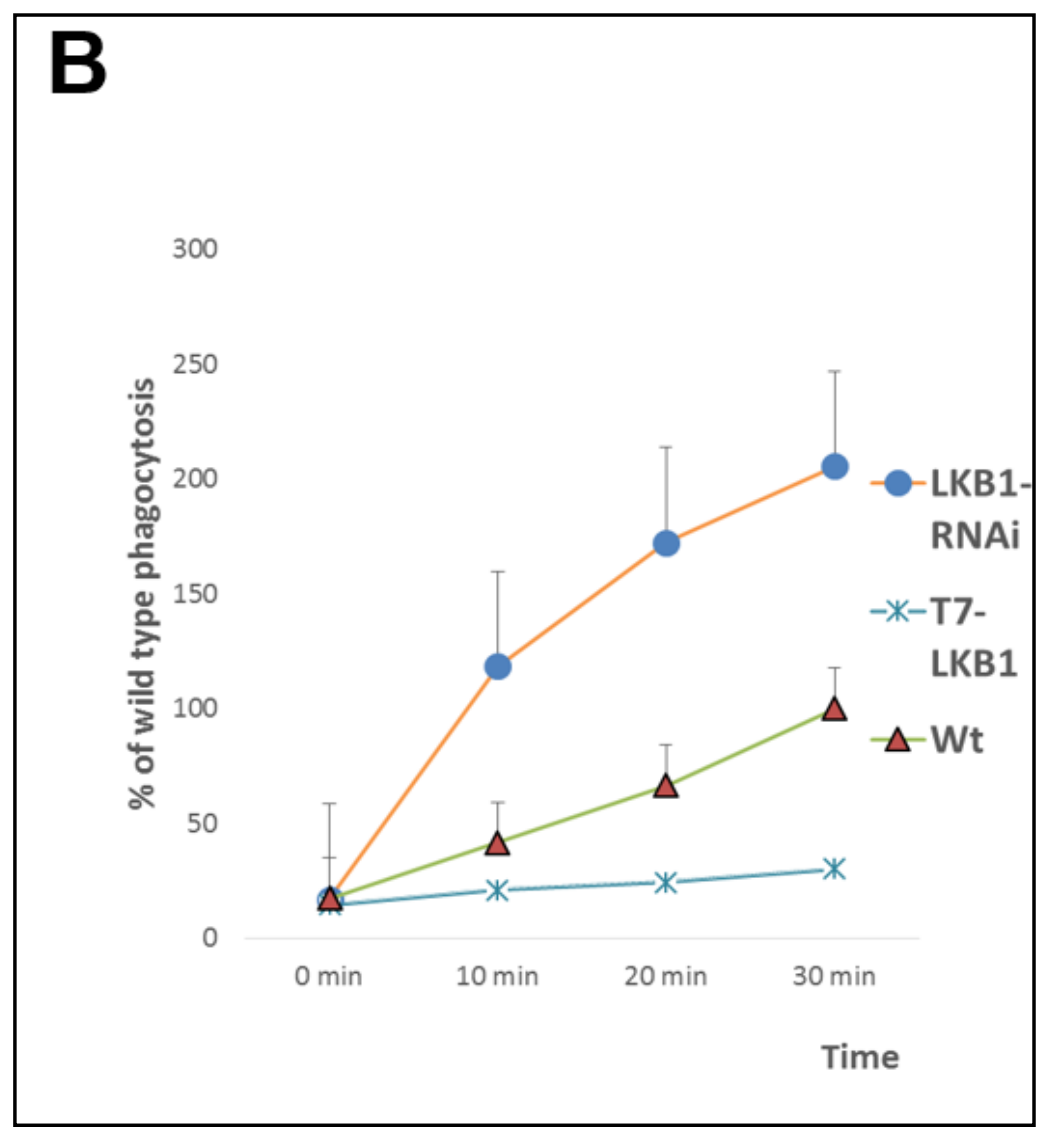

\section{FIGURE 7 PHAGOCYTOSIS OF TRITC YEAST BY LKB1 KNOCKDOWN CELLS AND CELLS OVER EXPRESSING LKB1.}

A) LKB1 knockdown cells and wild type cells transfected with a LKB1 over expresser with a T7 tag (T7 LKB1) were compared to the wild type cells, LKB1 displayed increased number of TRITC-yeast uptake when confirmed under a Fluorescent microscope. Cells transfected with the T7 LKB1 over expresser displayed a lower uptake number of TRITC yeast when compared to the wild type cells. B) To quantify the results from the Fluorescent microscope, the cells were treated with TRITC labelled yeast and quenched with tryphan blue. The assay was quantified using a spectrofluorometer at the wave length of Ex 515 and Em 474. The results correlated with the fluorescent microscope images confirming that Knock down of LKB1 increased the TRITC yeast particle uptake whereas over expressing LKB1 decreased the rate of phagocytosis dramatically as compared to wild type cells. 


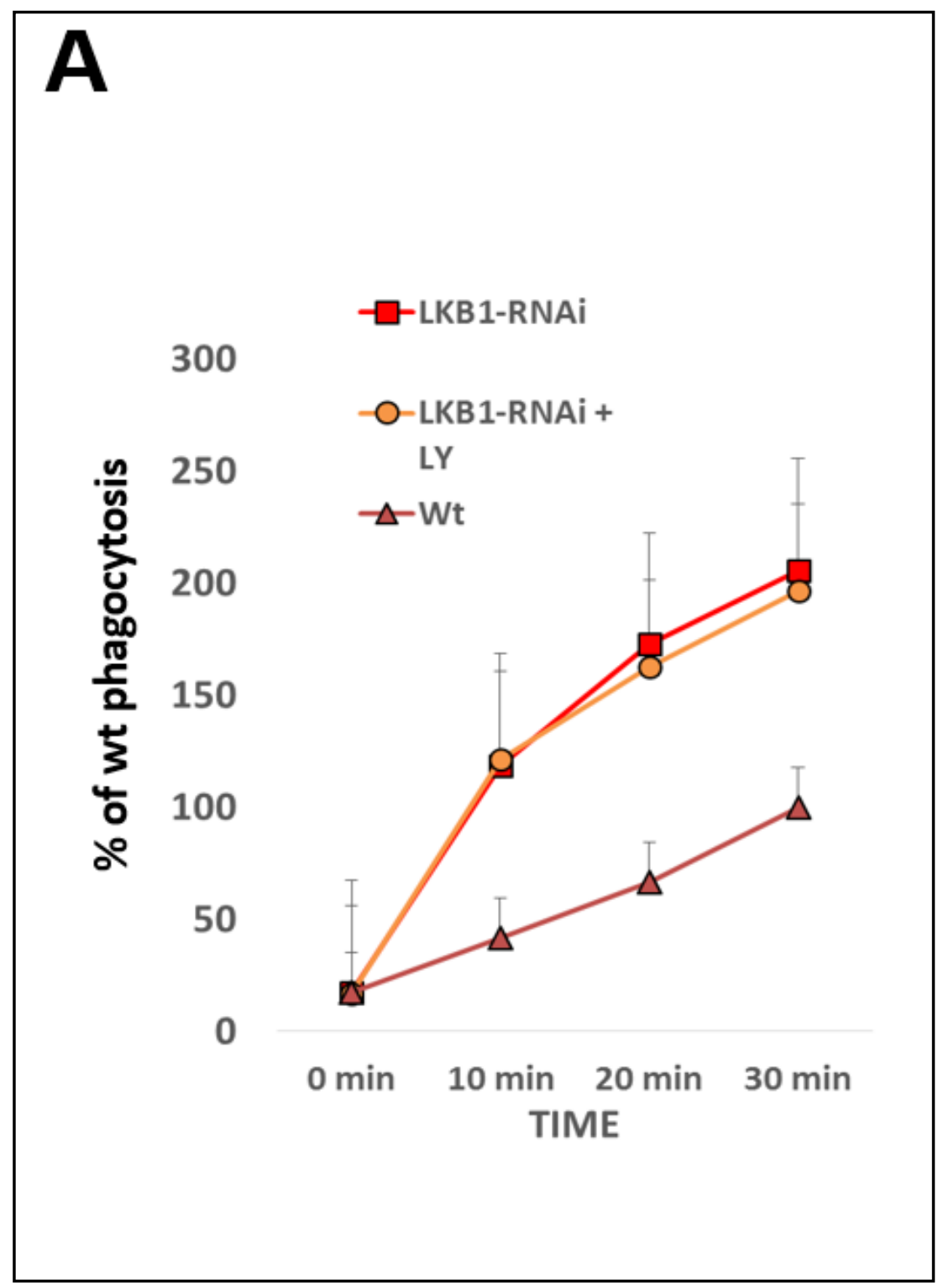




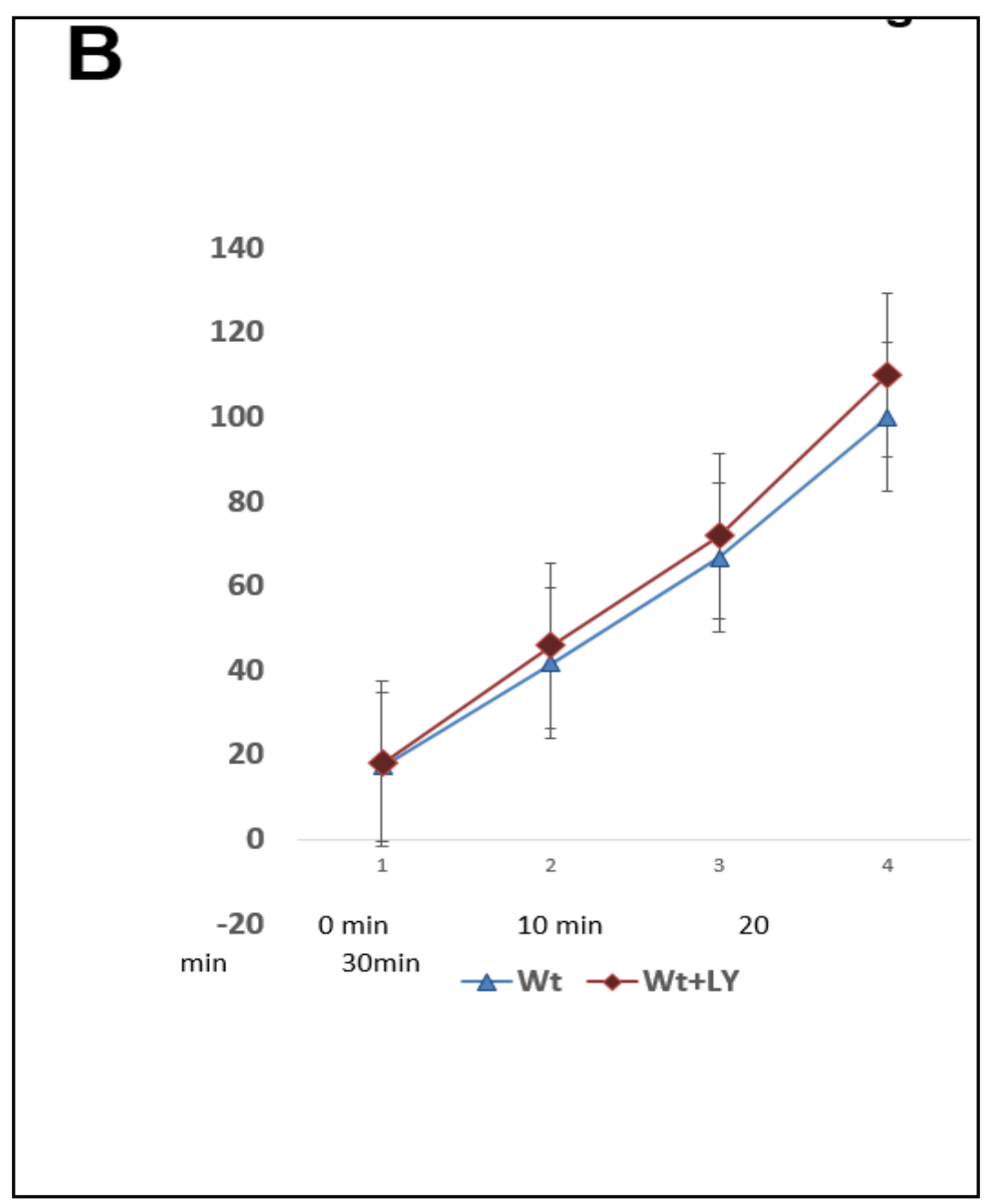




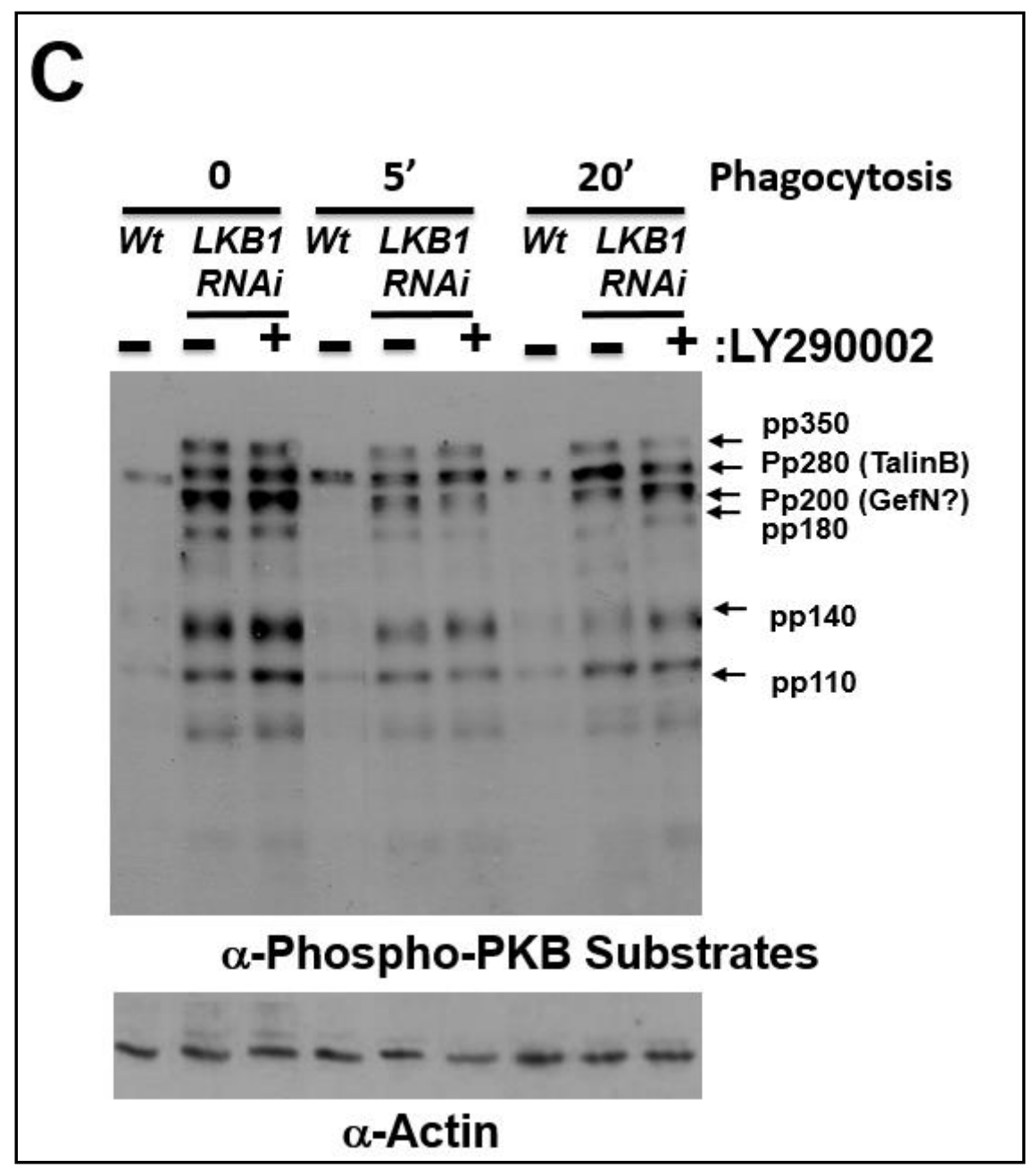

\section{FIGURE 8 LKB1 KNOCKDOWN CELLS SHOW ELEVATED LEVELS OF PHAGOCYTOSIS OF TRITC YEAST.}

A) LKB1 knockdown cells mixed with TRITC yeast and quantified using a fluorimeter. The rate of phagocytosis did not significantly change in LKB1 cells after the addition of the PI3 kinase inhibitor LY 294002 B) Phagocytosis of wildtype cells in the presence and absence of LY294002. The rate of phagocytosis was unaffected when wild type cells were treated with the PI3K inhibitor LY. C) PKB substrate phosphorylation in LKB1 knockdown cells treated with yeast and lysed at different time points. When compared to the wild type cells, The substrate phosphorylation was higher. The band at pp200 was exceptionally higher in intensity which could be GefN and the other band which is exceptionally higher is pp140 which could be PakA. 


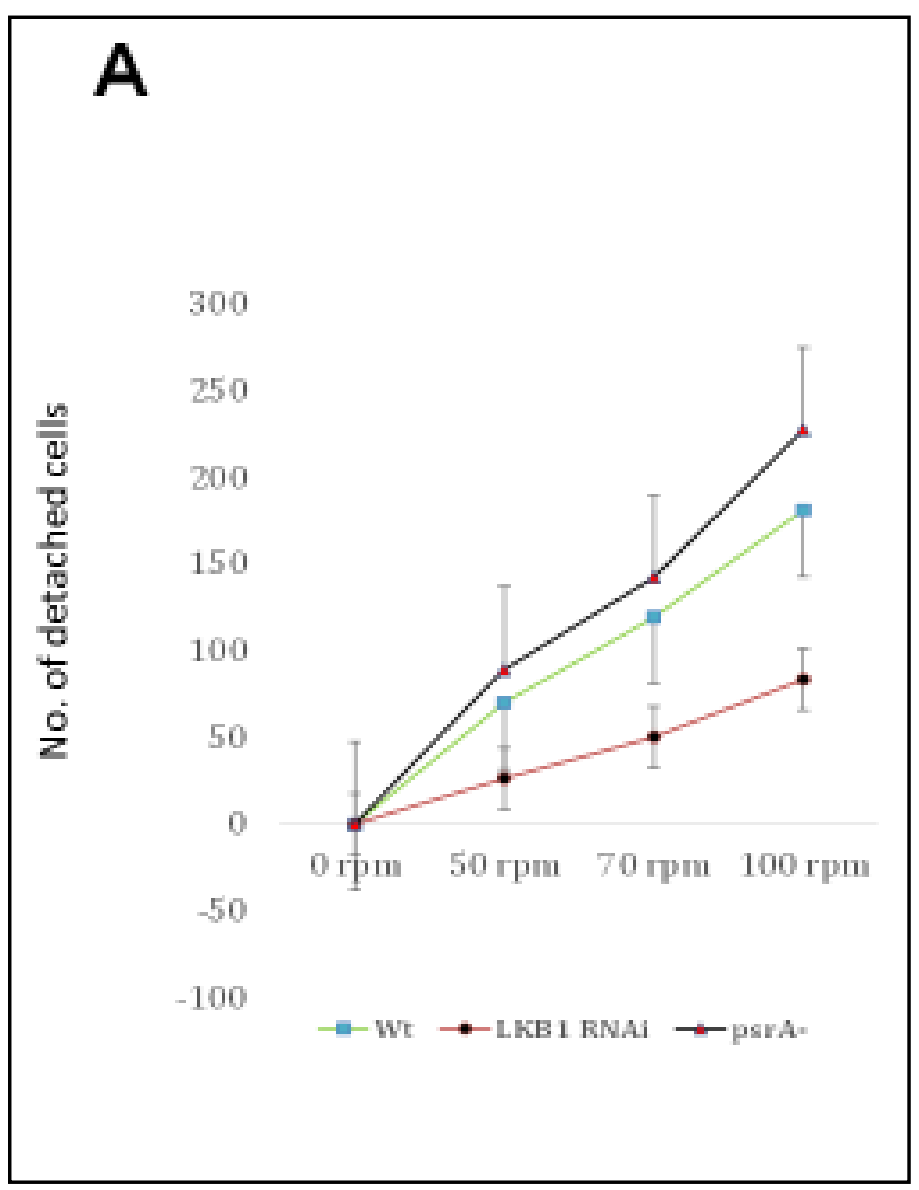




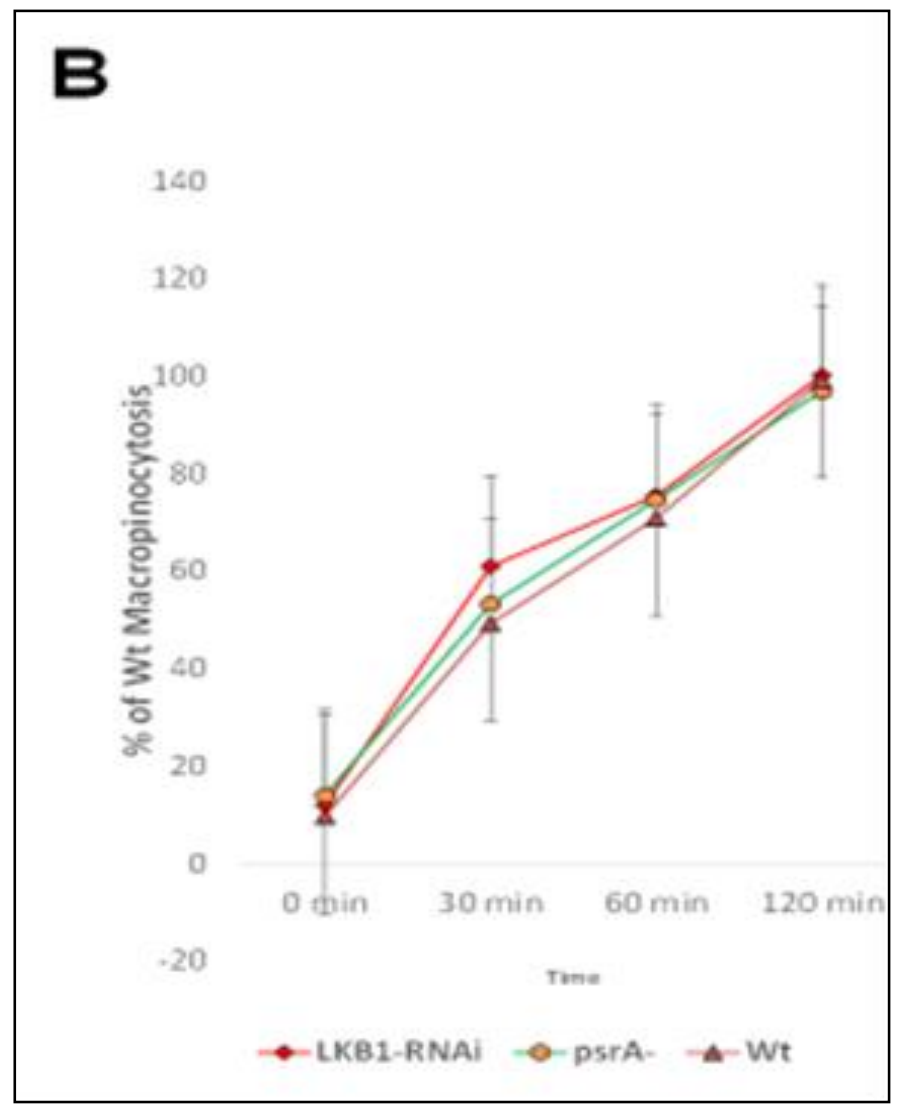

\section{FIGURE 9 ADHESION AND FLUID UPTAKE}

A) Wild type, and LKB1 knockdown were incubated to adhere to a substratum and were shaken at $50 \mathrm{rpm}, 70 \mathrm{rpm}$ and $100 \mathrm{rpm}$ to determine the ability of the cells to adhere to the substrate at different speed and compared to wild type cells. psrA-cells displayed a lower adhesion to the substratum whereas LKB1 knockdown cells adhered more strongly as compared to the wild type cells B) Wild type, LKB1 knock down and psrA-cells treated with FITC dextran and fluid uptake was measured using a fluorimeter. There no significant defect in the fluid uptake by $p s A^{-}$and LKB1 knock down cells 


\subsection{Discussion}

As shown earlier that suppression of LKB1 increased phagocytosis of heat inactivated yeast cells, while overexpression of LKB1 suppressed the activity (Fig. 6). Examination of the PKBs substrates phosphorylation pattern of LKB1-RNAi cells uncovered that these cells suffer from high basal level of PKBs substrates phosphorylation in a LY294002 insensitive manner, which is distinct from that of the psrA- cells (Fig. 7). psrA- cells displayed high level of PKBs activity, of which upstream activators PI3K and TorC2 are sensitive to LY294002, and so the restoration of phagocytosis and attenuation of PKBs substrate phosphorylation of psrA-cells upon LY294002 was reasonable. The phosphorylation level and the pattern of LKB1-RNAi cells were not identical with those of psrA- cells. LKB1-RNAi cells displayed more severe upregulation of GefN and PakA, where as TalinB was the most striking target of dysregulation in psrA- cells. Cell adhesion assay, however, demonstrated that psrA- cells are capable of wild type level adhesion activity even with higher level of TalinB phosphorylation (Fig. 8). Increased phagocytosis of LKB1-RNAi cells is partially consistent with the previous report that overexpression of the full length PakA in wild type cells increased phagocytosis up to $30 \%$ (muller-Taubenberger, et al., 2002). The other PKBs substrates showing outstanding phosphorylation is GefN, of which target Ras proteins are yet to be identified, unfortunately. In addition, LKB1-RNAi cells demonstrated high level of cell adhesion (Fig. 8) unlike psrA- cells, which also displayed high level of TalinB phosphorylation. 
We speculate that the hyperphosphorylation of GefN and PakA, and stronger adhesion may all contribute to the upregulated the phagocytic activity of LKB1-RNAi cells.

As mentioned earlier, the traditional TSC complex mediated signaling pathway characterized in mammalian systems predicts that LKB1 will suppress TorC2 activity. However, TorC2 suppression was shown to enhance the phagocytic activity in Dictyostelium, which is inconsistent with the prediction. Considering that TSC2 mediated regulation is limited to the TorC1, but not TorC2, in mammalian system, and that the exact mechanism of TorC2 mediated inhibition of phagocytosis is yet to be defined, more extensive investigation will be necessary to fully understand the molecular nature of LKB1 and TorC1 and TorC2 complex interaction.

We prefer the view that the proper regulation of the phosphorylation pattern of specific PKBs substrates is likely more important determinant to accommodate event specific FActin remodeling activities.

\subsection{References}

Boudeau, J., Scott, J. W., Resta, N., Deak, M., Kieloch, A., Komander, D., ... Alessi, D. R. (2004). Analysis of the LKB1-STRAD-MO25 complex. Journal of Cell Science, 117(Pt 26), 6365-6375.

Chartier, N. T., Salazar Ospina, D. P., Benkemoun, L., Mayer, M., Grill, S. W., Maddox, A. S., \& Labb??, J. C. (2011). PAR-4/LKB1 mobilizes nonmuscle myosin through anillin to regulate $\mathrm{C}$. elegans embryonic polarization and cytokinesis. Current Biology, 21(4), 259-269

Lacher, M. D., Pincheira, R. J., \& Castro, A. F. (2011). in Tuberous Sclerosis Complex and Cancer, (August), 211-216.

Martin, S. G., \& St Johnstone, D. (2003). A role for Drosophila LKB1 in anteriorposterior axis formation and epithelial polarity. Nature, 421(January), 379-384. 
Mehenni, H., Gehrig, C., Nezu, J., Oku, a, Shimane, M., Rossier, Antonarakis, S. E. (1998). Loss of LKB1 kinase activity in Peutz-Jeghers syndrome, and evidence for allelic and locus heterogeneity. American Journal of Human Genetics, 63(6), 1641-50.

Miranda, L., Carpentier, S., Platek, A., Hussain, N., Gueuning, M. A., Vertommen, Horman, S. (2010). AMP-activated protein kinase induces actin cytoskeleton reorganization in epithelial cells. Biochemical and Biophysical Research Communications, 396(3), 656-661.

Mirouse, V., Swick, L. L., Kazgan, N., St. Johnston, D., \& Brenman, J. E. (2007). LKB1 and AMPK maintain epithelial cell polarity under energetic stress. Journal of Cell Biology, 177(3), 387-392.

Shaw, R. J., Bardeesy, N., Manning, B. D., Lopez, L., Kosmatka, M., DePinho, R. A., \& Cantley, L. C. (2004). The LKB1 tumor suppressor negatively regulates mTOR signaling. Cancer Cell, 6(1), 91-99. http://doi.org/10.1016/j.ccr.2004.06.007

Sebbagh, M., Santoni, M. J., Hall, B., Borg, J. P., \& Schwartz, M. A. (2009). Regulation of LKB1/STRAD Localization and Function by E-Cadherin. Current Biology, 19(1), $37-42$

Veeranki, S., Hwang, S.-H., Sun, T., Kim, B., \& Kim, L. (2011). LKB1 regulates development and the stress response in Dictyostelium. Developmental Biology, 360(2), $351-7$

Woods, A., Johnstone, S. R., Dickerson, K., Leiper, F. C., Fryer, L. G. D., Neumann, D. Carling, D. (2003). LKB1 Is the Upstream Kinase in the AMP-Activated Protein Kinase Cascade. Current Biology, 13(22), 2004-2008.

Xu, X., Omelchenko, T., \& Hall, A. (2010). LKB1 tumor suppressor protein regulates actin filament assembly through Rho and its exchange factor Dbl independently of kinase activity. BMC Cell Biology, 11, 77 . 


\section{CHAPTER 4 CONCLUSION AND FUTURE DIRECTION}

\subsection{Conclusions}

Dictyostelium discoideum has been widely used as a model organism for studying multiple cellular events such as cell differentiation, morphogenesis, chemotaxis, and host-pathogen interactions. Dictyostelium cells not only provide multiple experimental advantages such as genetic amenability, but also contain a large number of regulatory proteins that are conserved throughout the whole metazoans (Maniak 2002). Furthermore, Dictyostelium cells are professional phagocytes that engulf various types and sizes of particles with significantly high uptake rate compared to mammalian phagocytes such as neutrophils and macrophages (Vogel et al. 1980).

Phagocytosis and micropinocytosis are signaling events that are subjected to a number of regulatory means. Both processes are actin-dependent and clathrinindependent and performed normally by specialized cells such as neutrophils, macrophages, and free-living amoebas such as Dictyostelium. Macropinocytosis is performed by dendritic cells in the mammalian system. These processes, however, can be induced in several pathogens: non-phagocytic $M$ cells in the epithelial tissue exhibited phagocytic activity by Salmonella enterica and human A431 cells displayed macropinocytosis upon interaction with Vaccinia virus (Mercer \& Helenius 2009)

The mechanism of phagocytosis itself has been a major focus of interest for many years. Extensive studies by numerous laboratories uncovered multiple receptors and their downstream effectors that modulate signaling cascade that converges to the F-Actin remodeling events as mentioned earlier in Chapter 1. Considering that both phagocytosis 
and chemotaxis are the processes that modulate F-Actin remodeling activity according the signals generated by membrane receptors in response to either cell-adhesion to a particle or external chemoattractants, the mechanisms obtained from chemotaxis would be a great benchmark to gain an insight on the regulatory mechanism of phagocytosis.

In this study, we uncovered that RasC, LKB1, and PP2A/B56 proteins are critical regulators affecting $\mathrm{PKB}$ function and thus F-actin remodeling in the context of particle uptake in Dictyostelium. Interestingly, these proteins also affect chemotaxis as well, indicating some mechanical redundancies between the two processes. It would be significant to determine if these regulatory proteins also affect those processes in mammalian systems.

In this study we determined that $\mathrm{RasC}$ has a positive effect on both phagocytosis and macropinocytosis. The $\operatorname{ras} C$ null mutants displayed compromised phagocytosis and macropinocytosis. We also showed that the other Ras proteins such as RasG and RasD have no effects on the phagocytosis. These null mutants showed no defect on phagocytosis, probably because of the active RasC mediated signaling. Future study will further uncover the redundancies and idiosyncrasies of these Ras proteins in the contexts of the phagocytosis. Considering that higher mammals have significantly more Ras proteins than Dictyostelium, delineation of the function of the above mentioned three Ras proteins would provide a benchmark for the investigation of the Ras mediated modulation of phagocytosis in human.

In addition to Ras Proteins, we also uncovered that Dictyostelium B56, the regulatory subunit of the heterotrimeric PP2A system, plays a positive role in 
phagocytosis while the Liver Kinase B (LKB1) has an inhibitory effect on phagocytosis. However, these proteins showed no phenotype on the fluid phase uptake.

The studies regarding involvement of the PI3K on the phagocytosis were not consistent. Some of the studies showed decrease in phagocytosis on PI3K inhibition with LY294002 while others showed no effect on phagocytosis. One of the problems is that these studies utilized diverse sizes and types of particles that could be internalized through different types of receptors.

There have been at least two distinct types of phagocytic receptors identified in Dictyostelium: the receptor which binds to the latex beads is through hydrophobic interaction and is called the non-specific receptor and the other receptor is believed to recognize the terminal glucosides on bacteria and yeast. A study demonstrated that latex beads could be internalized through PIP3 independent and dependent manner (Giorgione and Margaret Clarke, 2008 ). The mechanistic details of latex bead uptake remains to be clarified.

In the current study, heat-killed yeast particles were used which are significantly bigger than other commonly used particles such as latex bead or bacteria . It was possible to visualize the PI3K product, PIP3, transiently enriched at the rim of the phagocytic cup harboring a yeast particle. However, the inhibition of PI3K with LY294002 in wild type and cells expressing LKB1-RNAi displayed no clear phenotype. In contrast, $p s r A^{-}$cells displayed near complete rescue of the phagocytosis defect and concomitant restoration of the PKBs substrate phosphorylation pattern upon PI3K inhibition. This could be due to the inhibitory effect of LY294002 on both PIP3 generation and TorC2. Inhibition of PIP3 generation will affect PKBA and that of TorC2 will affect both PKBA and PKBR1. Wild 
type cells with potent PP2A/B56 could still suppress LY294002 mediated upregulation of PKBs, but cells lacking PP2A would be much more sensitive to LY294002 and display altered pattern of PKBs substrate phosphorylation. These together, we speculate that PIP3 is likely modulating phagocytosis by modulating PKBs substrate phosphorylation, but not the phagocytic cup formation.

In the current study we uncovered that LKB1 displayed an inhibitory effect on phagocytosis. LKB1 knock-down cells had several folds higher rate of phagocytosis and displayed significantly higher level of PKB substrate phosphorylation, but in a pattern that are different from that of the psrA- cells. This could be related to some of the PKB substrates which previously have been shown to enhance phagocytosis like PakA and Talin (Bosgraaf \& van Haastert 2006). There was higher adhesion observed in LKB1 knockdown cells indicating that LKB1 kinase could be regulating phagocytosis via Talin.

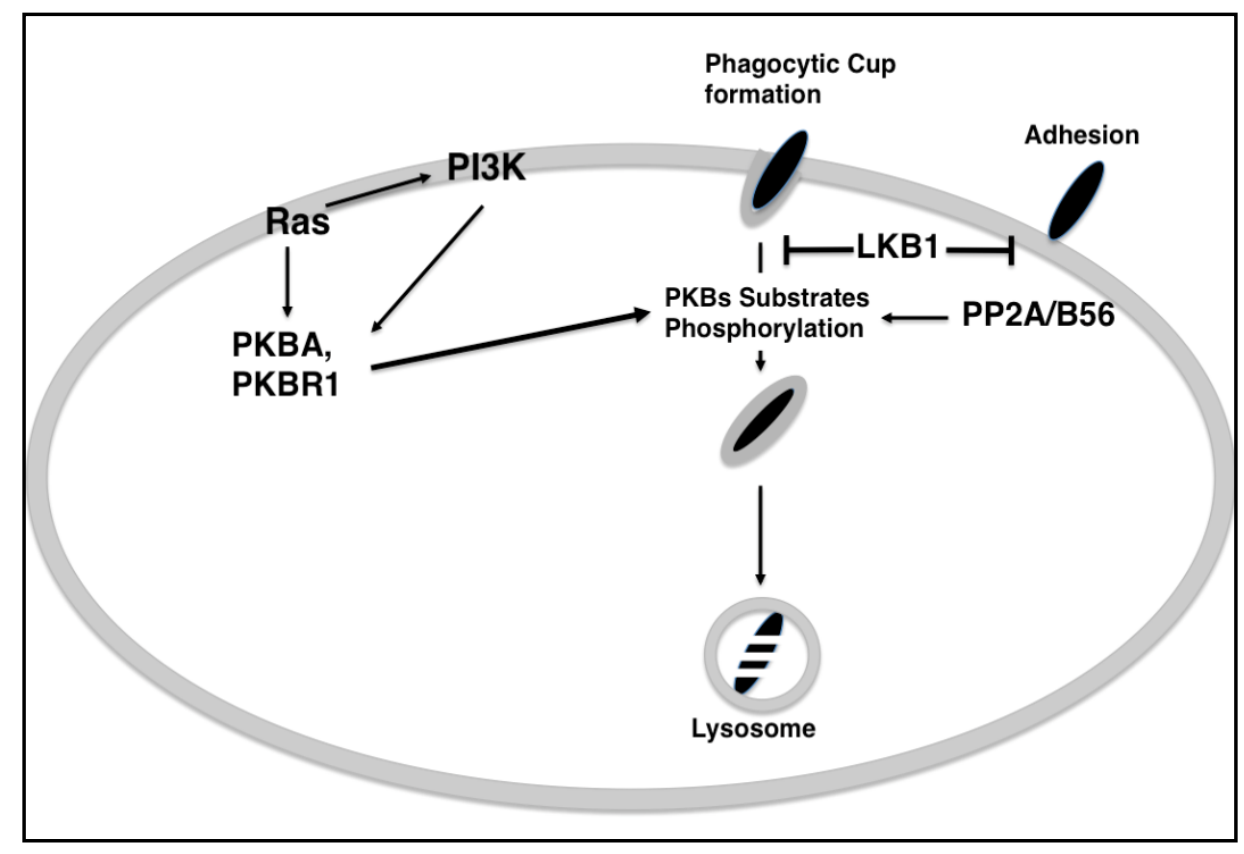




\section{Figure 10 SCHEMATIC CONCLUSION}

\section{Overall schematic representations of the regulatory circuits of phagocytosis presented in this report.}

\subsection{Dictyostelium as a model for Host- pathogen interaction studies}

In mammalian systems, the primary line of defense includes a physical barrier such as skin and phagocytic immune cells in the mucous membrane. Many infectious pathogens can breach this mechanism of defense by manipulating several aspects of phagocytosis. Some could avoid phagocytosis and others could alter phagosome maturation, either case could induce serious consequences in human body. Recently emerging pathogens that are resistant to multiple antibiotics could potentially be controlled by appropriate phagocytic activity against them.

One of the striking features of Dictyostelium is its broad range of bacterial species that can be engulfed: an early studies (Depraite`re and Darmon, 1978) showed that Dictyostelium cells can engulf a large number of bacteria that are either Gram positive or Gram negative. Twenty-three gram negative and forty-five gram positive bacteria were classified according to their effect on Dictyostelium. Dictyostelium cells did not phagocytosed Bacillus anthracis, but were killed upon infection with Pseudomonas aeruginosa and Bacillus thuringiensis. Several other bacterial species that belong to the phylum Gamma Proteobacteria such as such Serratia marcescens, Pseudomonas aeruginosa, Pseudomonas cepacia, Pseudomonas rubescens, and ones that belong to Firmicutes Phylum such as Bacillus thuringiensis, Bacillus laterosporus, and Listeria monocytogenes were uncovered to be toxic to Dictyostelium. 
As discussed before, there are many pathogens that affect the cells of the immune system like macrophages and neutrophils. Having a similar mechanism of particle uptake and fluid uptake to the mammalian cells, Dictyostelium has been used to study host pathogen interactions and study the effect of pathogen infection on the phagocytosis pathway (Peracino et al. 2010). Previously, Dictyostelium has been used to investigate the overall effects of infection with pathogens such as L. pneumophilia, M. tuberculosis and S. typhirium(Sillo et al. 2011; Steinert 2011) . These are human pathogens and thus the study of such pathogens and their invasive mechanisms provide invaluable insight for the development of drugs and vaccines for the eradication of such disease.

The natural habitat of Dictyostelium cells is the soil, and thus soil living bacteria are highly likely ingested by Dictyostelium cells. Some of the soil living bacteria include Bacillus and Clostrium, both of which could lead to severe human diseases and they are likely phagocytosed by Dictyostelium, it would be informative to uncover the mechanism and consequences of host-pathogen interactions utilizing these bacteria as a pathogen (Lima et al. 2014).

The current knowledge of the different proteins regulating the phagocytosis and molecular tools developed could be useful to study the molecular mechanism through which the pathogen invades. This study can be used to develop therapy and vaccines to combat these pathogens. The knowledge of the evolutionarily conserved regulatory proteins, such as Ras, PP2A/B56, LKB1, and PKBs (these are the main topic of this study), can be used as useful and tractable tools to further uncover the mechanisms of diverse pathogen-host interactions. 


\subsection{References}

Alibaud, L., Kuuhler, T., Coudray, A., Prigent-Combaret, C., Bergeret, E., Perrin, Cosson, P. (2008). Pseudomonas aeruginosa virulence genes identified in a Dictyostelium host model. Cellular Microbiology, 10(3), 729-740

Bozzaro, S., \& Eichinger, L. (2011). The professional phagocyte Dictyostelium discoideum as a model host for bacterial pathogens. Current Drug Targets, 12(7), 94254.

Clarke, M. (2010). Recent insights into host-pathogen interactions from Dictyostelium. Cellular Microbiology.

Depraitère, C. C., \& Darmon, M. M. (1978). [Growth of "Dictyostelium discoideum" on different species of bacteria (author's transl)]. Ann. Microbiol. (Paris), 129 B(3), 451-461.

Farbrother, P., Wagner, C., Na, J., Tunggal, B., Morio, T., Urushihara, H., ... Eichinger, L. (2006). Dictyostelium transcriptional host cell response upon infection with Legionella. Cellular Microbiology, 8(3), 438-456. http://doi.org/10.1111/j.14625822.2005.00633.x

Froquet, R., Lelong, E., Marchetti, A., \& Cosson, P. (2009). Dictyostelium discoideum: a model host to measure bacterial virulence. Nature Protocols, 4(1), 25-30.

Lima, W. C., Balestrino, D., Forestier, C., \& Cosson, P. (2014). Two distinct sensing pathways allow recognition of Klebsiella pneumoniae by Dictyostelium amoebae. Cellular Microbiology, 16(3), 311-323.

Maniak, M. (2002). Conserved features of endocytosis in Dictyostelium. International Review of Cytology, 221, 257-287

Peracino, B., Borleis, J., Jin, T., Westphal, M., Schwartz, J. M., Wu, L., ... Bozzaro, S. (1998). G protein $\beta$ subunit-null mutants are impaired in phagocytosis and chemotaxis due to inappropriate regulation of the actin cytoskeleton. Journal of Cell Biology, 141(7), $1529-1537$.

Sillo, A., Matthias, J., Konertz, R., Bozzaro, S., \& Eichinger, L. (2011). Salmonella typhimurium is pathogenic for Dictyostelium cells and subverts the starvation response. Cellular Microbiology, 13(11), 1793-1811. http://doi.org/10.1111/j.14625822.2011.01662.x

Steinert, M. (2011). Pathogen-host interactions in Dictyostelium, Legionella, Mycobacterium and other pathogens. Seminars in Cell and Developmental Biology. 
Vogel, G., Thilo, L., Schwarz, H., \& Steinhart, R. (1980). Mechanism of phagocytosis in Dictyostelium discoideum: Phagocytosis is mediated by different recognition sites as disclosed by mutants with altered phagocytotic properties. Journal of Cell Biology, 86(2), 456-465. 
VITA

MUJATABA RAHIMAN SHARIEF

Born, Mysore, Karnataka, India

2004-2007

B.Sc in Biotechnology

Bangalore University

Bangalore, Karnataka, India

2007-2009

M.Sc in Biotechnology

Bangalore University

Bangalore, Karnataka, India

2009-2010

Project Assistant

National Institute of Animal Nutrition and

Physiology

Bangalore, Karnataka, India

2011-2016

Teaching Assistant

Florida International University

Miami, Florida, USA

2011-2016

Doctoral Candidate

Florida International University

Miami, Florida, USA

\section{PUBLICATIONS AND PRESENTATIONS}

Rahiman Sharief, M and Kim L. (2015). Regulation of Phagocytosis by PP2A/B56 and LKB1 in Dictyostelium Discoideum. $17^{\text {th }}$ annual Biomedical and Comparitive Immunology symposium, Florida International University, Miami, FL (Oral presentation). 